NASA Technical Memorandum 105251

AIAA-91-3578

\title{
Analytical Study of Nozzle Performance for Nuclear Thermal Rockets
}

Kenneth O. Davidian and Kenneth J. Kacynski

Lewis Research Center

Cleveland, Ohio

Prepared for the

Conference on Advanced Space Exploration Initiative Technologies cosponsored by AIAA, NASA, and OAI

Cleveland, Ohio, September 4-6, 1991

\section{N/SA}




\title{
ANALYTICAL STUDY OF NOZZLE PERFORMANCE FOR NUCLEAR THERMAL ROCKETS
}

\author{
Kenneth O. Davidian and Kenneth J. Kacynski \\ National Aeronautics and Space Administration \\ Lewis Research Center \\ Cleveland, Ohio 44135-3191
}

\begin{abstract}
$\underline{\text { Abstract }}$
Nuclear propulsion has been identified as one of the key technologies needed for human exploration of the Moon and Mars. The Nuclear Thermal Rocket (NTR) uses a nuclear reactor to heat hydrogen to a high temperature followed by expansion through a conventional convergent-divergent nozzle. A parametric study of NTR nozzles was performed using the Rocket Engine Design Expert System (REDES) at the NASA Lewis Research Center. REDES used the JANNAF standard rigorous methodology to determine nozzle performance over a range of chamber temperatures, chamber pressures, thrust levels, and different nozzle configurations. A design condition was set by fixing the propulsion system exit radius at five meters and throat radius was varied to achieve a target thrust level. An adiabatic wall was assumed for the nozzle, and its length was assumed to be $80 \%$ of a $15^{\circ}$ cone.

The results of this study conclude that although the performance of the NTR, based on infinite reaction rates, looks promising at low chamber pressures, finite rate chemical reactions will cause the actual performance to be considerably lower. Parameters which have a major influence on the delivered specific impulse value include the chamber temperature and the chamber pressures in the high thrust domain. Other parameters, such as two-dimensional and boundary layer effects, kinetic rates and number of nozzles, affect the deliverable performance of an NTR nozzle to a lesser degree. For a single nozzle, maximum performance of 930 seconds and 1030 seconds occur at chamber temperatures of 2700 and $3100 \mathrm{~K}$, respectively.
\end{abstract}

\section{Introduction}

Nuclear propulsion has been identified as one of the key technologies needed for human exploration of the Moon and Mars. ${ }^{1}$ Successful application of any mission using an NTR depends on high delivered performance, because the weight of a nuclear reactor must be compensated for by reduced propellant requirements. To date, many different reactor design and operating conditions have been identified as a means of satisfying various mission scenarios. The different reactor operating conditions include both pressure and thrust range variations of nearly two orders of magnitude, and reactor temperatures operating up to the melting point of the fuel. ${ }^{2,3} \mathrm{With}$ such a variety of perceived operating conditions, a priori knowledge of anticipated nozzle performance at a certain reactor operating condition is important for design and evaluation purposes. Likewise, to design the optimum NTR system, the sensitivity of nozzle performance to reactor operating conditions is crucial.

The purpose of this paper is to investigate the effect of the various operating conditions on the NTR nozzle performance in a rigorous manner, and to identify the major parameters which affect the deliverable performance of an NTR nozzle. In order to determine their affect on the delivered nozzle performance of an NTR, a variety of operating parameters were investigated over a wide range of nozzle configurations. Chamber pressure $\left(\mathrm{p}_{c}\right)$, chamber temperature $\left(T_{c}\right)$, propulsion system thrust level $(\mathrm{F})$, and number of nozzles were investigated with four different combinations of nozzle performance codes to determine their 
Table 1. Analysis parameters and values.

\section{Parameter: Values}

Chamber Pressure:

$$
10,30,100,300,1000,3000 \text { psia }
$$

Chamber Temperature: $2700,2900,3100 \mathrm{~K}$

Propulsion System Thrust Level:

$10,30,100,300 \mathrm{Klb}_{\mathrm{f}}$

Number of Nozzles: $1,3,5,7$

effect on specific impulse $\left(\mathrm{I}_{\mathrm{sp}}\right)$. Ranges over which the parameters were varied are given in Table 1 . In each case, rocket nozzle performance calculations were made to determine the chemical equilibrium performance, and the detrimental effects of finiterate chemistry, two-dimensional flow, and boundary layer growth. A matrix was investigated using a computer code which conforms to the Joint Army-Navy-NASAAir Force (JANNAF) standardized methodology for determining chemical liquid rocket nozzle performance.

A nozzle cluster exit radius of 5 meters was used throughout the analysis. This radius corresponds to the payload bay size of the advanced launch vehicles formerly and currently under consideration for development (e.g., Shuttle-C and ALS). ${ }^{4}$ Using this criteria, the entire nozzle assembly could fit into the cargo bay of these vehicles. As will be shown, the use of this maximum practical nozzle cluster size as a design criteria corresponds to a nearly maximum performance condition.

In order to generate design study results with fixed exit area and thrust level as a test matrix parameter, a need existed to overcome the limitation of available codes which calculate nozzle thrust based on given input parameters. This was accomplished through the use of the Rocket Engine Design Expert System currently under development at the NASA Lewis Research Center. ${ }^{5}$ At each data point, the throat radius and area ratio of the nozzle was allowed to vary to meet the target thrust level constraint.

\section{Analysis and Results}

Results of the studies which describe the

Figure 1. Mole fraction of $\mathbf{H}_{2}$ for different chamber pressures at $T_{c}=3100 \mathrm{~K}$.

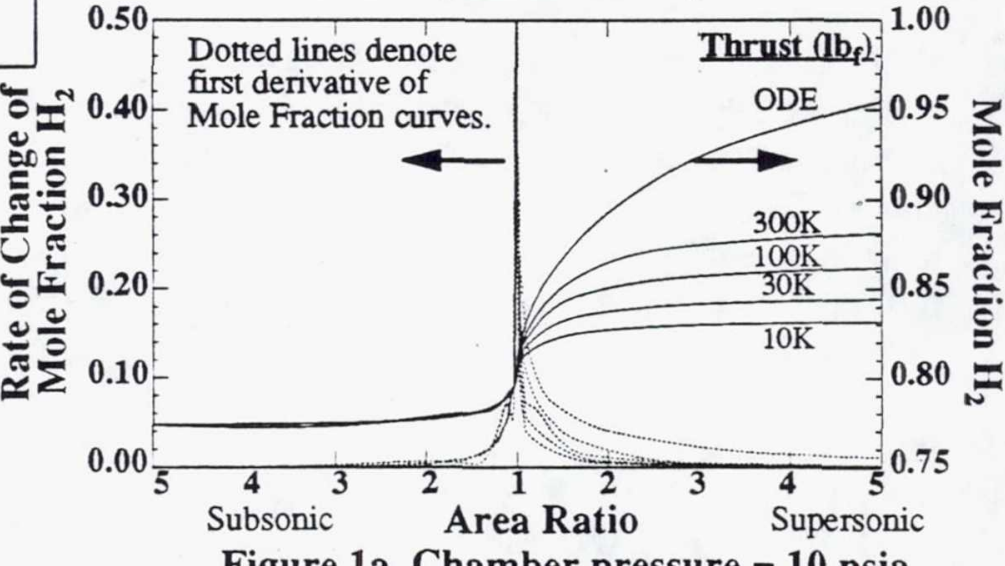

Figure 1a. Chamber pressure $=\mathbf{1 0}$ psia

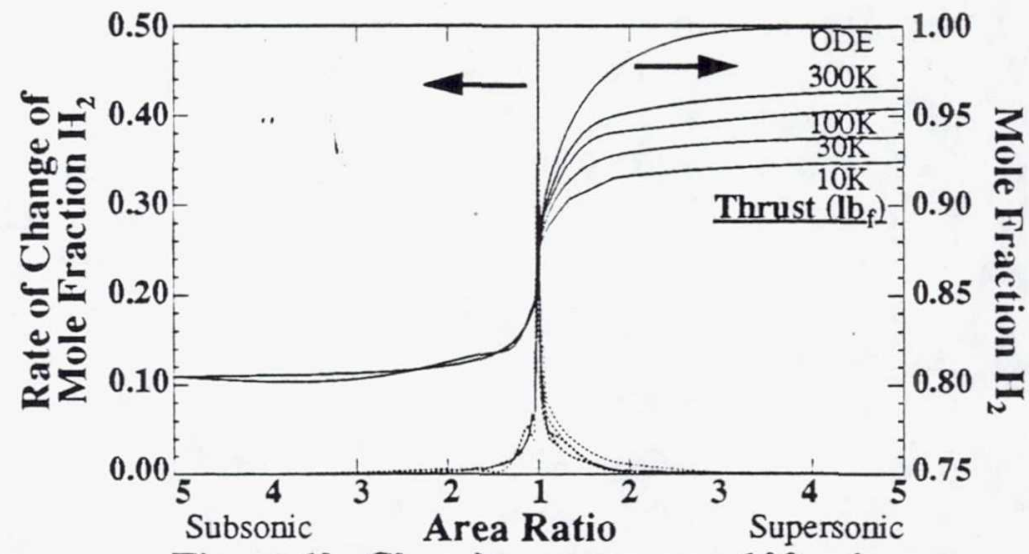

Figure 1b. Chamber pressure $=\mathbf{1 0 0}$ psia

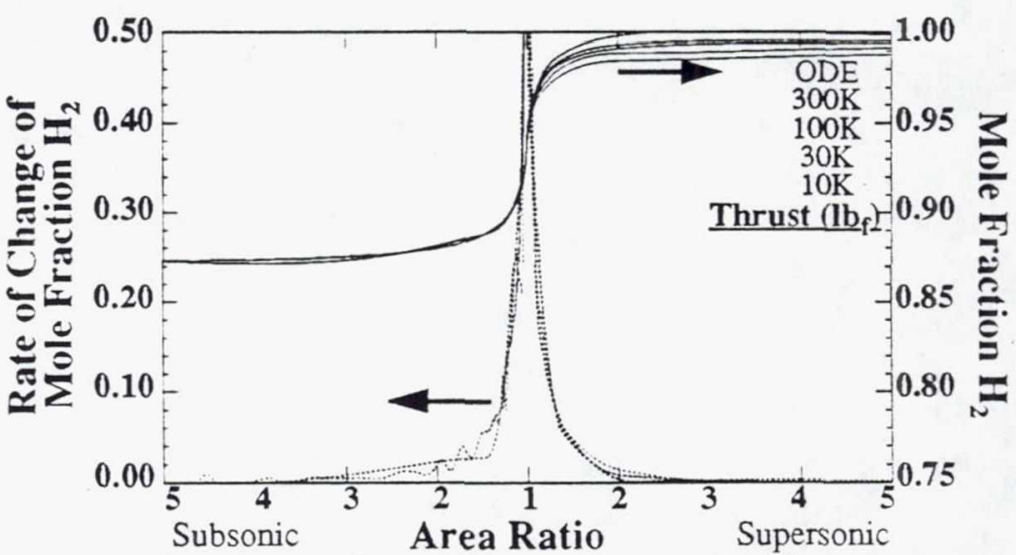

Figure 1c. Chamber pressure $=1000$ psia 
recombination of monatomic to diatomic hydrogen are presented and discussed first, since this phenomenon is the prime contributor to the NTR nozzle's high performance. Next, the effect of varying the operating parameters on nozzle geometry and performance are given. How performance is affected by utilizing multiple nozzles in a cluster is discussed next. Finally, the uncertainty of chemical recombination rates on nozzle performance is given.

\section{Hydrogen Recombination}

The energy release which accompanies the recombination of monatomic hydrogen $(\mathrm{H})$ to diatomic hydrogen $\left(\mathrm{H}_{2}\right)$ provides the high performance for which the low pressure NTR concept is known. Understanding the recombination process is key to understanding how the NTR performs.

Mole fractions of $\mathrm{H}_{2}$, computed using onedimensional infinite and one-dimensional finite chemical reaction rates, were plotted as a function of subsonic and supersonic area ratios for different thrust levels and $\mathrm{p}_{\mathrm{c}}$ values (Figure 1). In all cases, the $\mathrm{H}_{2}$ mole fraction starts at a minimum value in the chamber. The infinite and finite reaction rate results in this part of the chamber are identical because the residence time of the propellant is much greater than the time required for the reactions to reach equilibrium, thereby allowing the recombination reactions to reach equilibrium. As the flow expands, moving in Figure 1 from left to right along the curve toward the throat (where the area ratio equals one), and continuing along the supersonic portion of the curve, the rise in the $\mathrm{H}_{2}$ mole fraction indicates the recombination of $\mathrm{H}$ into $\mathrm{H}_{2}$. In all cases, it is seen that the larger thrust nozzles are closest to being in chemical equilibrium. This occurs because the larger thrust nozzles also correspond to larger throat dimensions, and a more gradual fluid acceleration rate. The more gradual acceleration rates allow appreciably more $\mathrm{H}$ recombination to occur, pushing performance toward the infinite reaction rate limit.
Superimposed on the recombination plots, in dotted lines, is the first derivative of the mole fraction curves. Where recombination occurs, the derivative is denoted by a non-zero value. Frozen conditions occur when the derivative is zero in the supersonic portion of the nozzle. As can be seen in Figures 1a, 1b, and 1c, the majority of $\mathrm{H}_{2}$ recombination and its associated energy release occurs in the near throat region.

\section{Nozzle Geometry}

A capability of the Rocket Engine Design Expert System (REDES), called the Thrust Dependent Engine Sizing (TDES) function ${ }^{6}$, iterated toward a desired thrust level while employing the rigorous JANNAF solution procedure ${ }^{7}$ to calculate nozzle $I_{\text {sp. }}$. A liquid rocket nozzle performance evaluation code, Two Dimensional Kinetics (TDK) ${ }^{8}$, was used for the entirety of this analysis.

Table 1 gives the parameters included in the study and their values. Geometric parameters which define the contraction and near-throat region of the convergent-divergent nozzle are given in Table 2. Other assumptions which were used to characterize the nozzle shape included:

- the nozzle contour was a parabola fitted to connect a tangent point on the downstream throat circle and a specific exit coordinate,

- the exit radius of the entire propulsion system package was set to be 5 meters,

- nozzle length was determined by

Table 2. Baseline geometric parameters.

\begin{tabular}{|cc|}
\hline Chamber Contraction Ratio $=$ & 5.00 \\
Nondimensional Throat Upstream & Radius of \\
Curvature $=$ & 2.0623 \\
Nondimensional Throat Downstream & Radius of \\
Curvature $=$ & 0.1900 \\
Throat Upstream Tangent Angle $=$ & $26.25^{\circ}$ \\
Throat Downstream Tangent Angle $=$ & $32.00^{\circ}$ \\
Nozzle Length $=80 \%$ of a $15^{\circ}$ Cone \\
\hline
\end{tabular}


Figure 2. Nozzle area ratio variation as a function of chamber pressure, for $T_{c}=3100 \mathrm{~K}$, one nozzle.

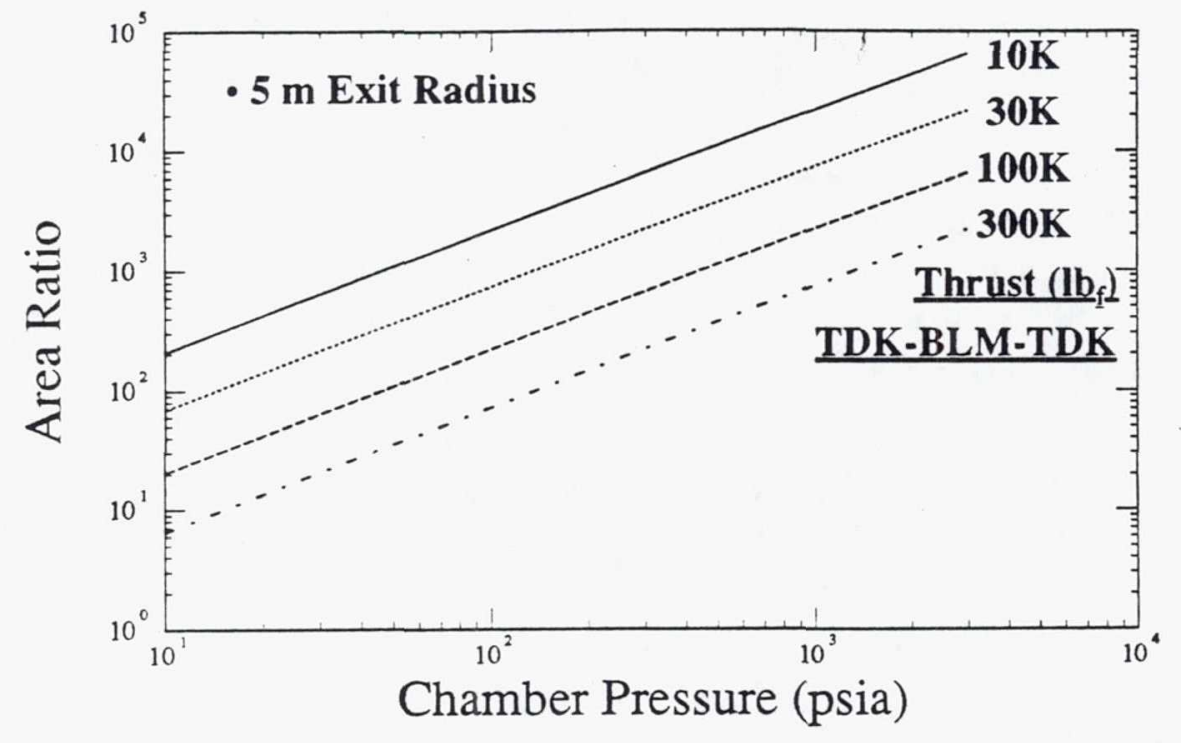

the TDES function of REDES to be $80 \%$ of a $15^{\circ}$ cone nozzle with the same throat radius, downstream radius of curvature, and area ratio, and is calculated from the following equation, ${ }^{9}$

- the boundary layer would become turbulent after the flow Reynold's number based on momentum thickness achieved a preset value of 360 .

$L_{n}=0.8 \times \frac{r_{t}(\sqrt{\varepsilon}-1)+R W T D(\sec \alpha-1)}{\tan \alpha}$

Because the TDES function within REDES kept the nozzle exit radius constant and varied the throat radius to arrive at a desired thrust level, the area ratio of the nozzle varied as a where $L_{n}$ is nozzle length, $r_{t}$ is the throat radius, $\varepsilon$ is the area ratio, RWTD is the downstream throat radius of curvature, and $\alpha$ is the cone half angle $\left(15^{\circ}\right.$ in this case), and

- there was no spacing between nozzles in the 3,5 , and 7 nozzle cases.

Boundary layer assumptions included:

- an adiabatic wall,

- equilibrium chemistry in the boundary layer,

- the standard JANNAF boundary layer loss methodology was used, and function of chamber pressure and thrust level. Figure 2 shows a typical plot of nozzle area ratio versus chamber pressure for all thrust levels for a chamber temperature of $3100 \mathrm{~K}$ and the single nozzle case. All plots of nozzle area ratio as a function of chamber pressure are given in Appendix.

As can be seen in Figure 2, nozzle area ratios of $60,000: 1$ result in some instances. This is due to the combination of low thrust, high chamber pressure, and the fixed exit area constraint. In practice, relaxation of the fixed area constraint would likely occur because of nozzle weight and performance considerations. Small area ratios, less than 10:1, occur at high thrust, low chamber pressure operating conditions.

Figure 3 shows the nozzle length trend for the same chamber temperature and number of 
nozzles as Figure 2. All nozzle length plots are given in Appendix. Nozzle lengths at low $\mathrm{p}_{c}$ levels are very sensitive to thrust level. Nozzle lengths for higher thrust levels are shorter than those for lower thrust levels, because of the lower area ratios for those nozzles. The difference, however, between the $10 \mathrm{Klb}_{\mathrm{f}}$ and the $300 \mathrm{Klb}_{\mathrm{f}}$ nozzle lengths decreases drastically and the nozzle lengths converge toward a single value as chamber pressure increases. This is the result of the area ratio increase with chamber pressure, due to the fixed exit area design condition. As area ratio increases, the nozzle length equation approaches a value of approximately $3 r_{e}$ (shown as the horizontal dashed line in Figure 3). For the single nozzle case, values converged toward a length of approximately 590 inches at high chamber pressures. In the case of three nozzles, the asymptotic length value is roughly 270 inches, for five nozzles, lengths approach 210 inches, and in the seven nozzle case, lengths converge toward a value of 200 inches.

\section{Nozzle Performance}

Equilibrium performance of a NTR nozzle can be predicted to exceed 1200 seconds as seen in the case presented in Figure 4.
However, equilibrium performance of a NTR nozzle must be decremented by real effects and performance losses which can be predicted using the JANNAF methodology, standardized nozzle performance code, TDK. ${ }^{8}$ TDK calculates performance decrements due to chemical kinetics, two-dimensional losses, and boundary layer growth. Other loss mechanisms, including mixing, vaporization and nonboundary layer heat losses, were assumed to be negligible, or not applicable to a nuclear thermal rocket nozzle simulation. After subtracting these losses from the equilibrium specific impulse $\left(I_{\mathrm{sp}}\right)$ values, the resulting performance was the delivered $\mathrm{I}_{\mathrm{sp}}$.

Results including all loss mechanisms were plotted to show NTR nozzle performance for the entire range of chamber pressures, chamber temperatures, and thrust levels. Figure 5 is a representative plot from the total set which were created over the range of parametric variables (Table 1). All plots are given in the Appendix.

To identify the magnitude of each loss mechanisms, nozzle performance was computed using each module of the TDK program in a sequential fashion. Isp values based on one-dimensional infinite chemical

Figure 3. Variation of nozzle length as a function of chamber pressure.

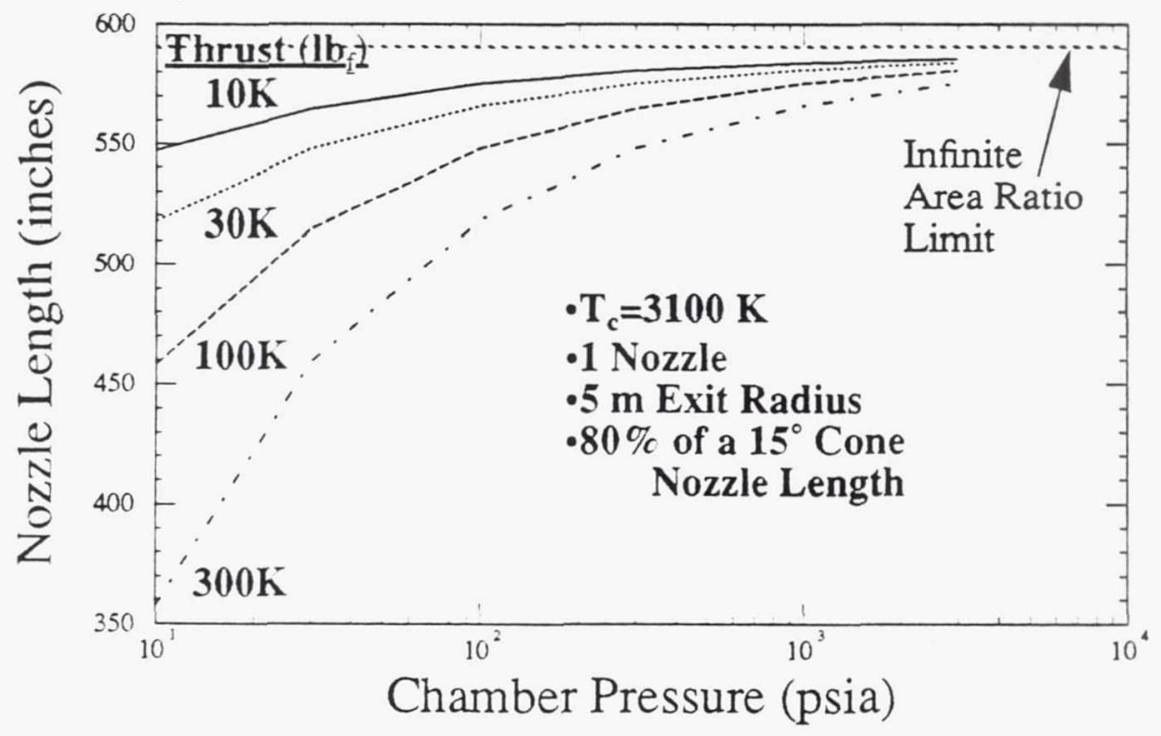


Figure 4. Theoretical equilibrium chemistry performance of a nuclear thermal rocket nozzle with exit radius of 5 meters. Chamber temperature $=3100 \mathrm{~K}$, thrust level $=\mathbf{1 0 , 0 0 0} \mathrm{lb}_{\mathrm{f}}$, single nozzle case.

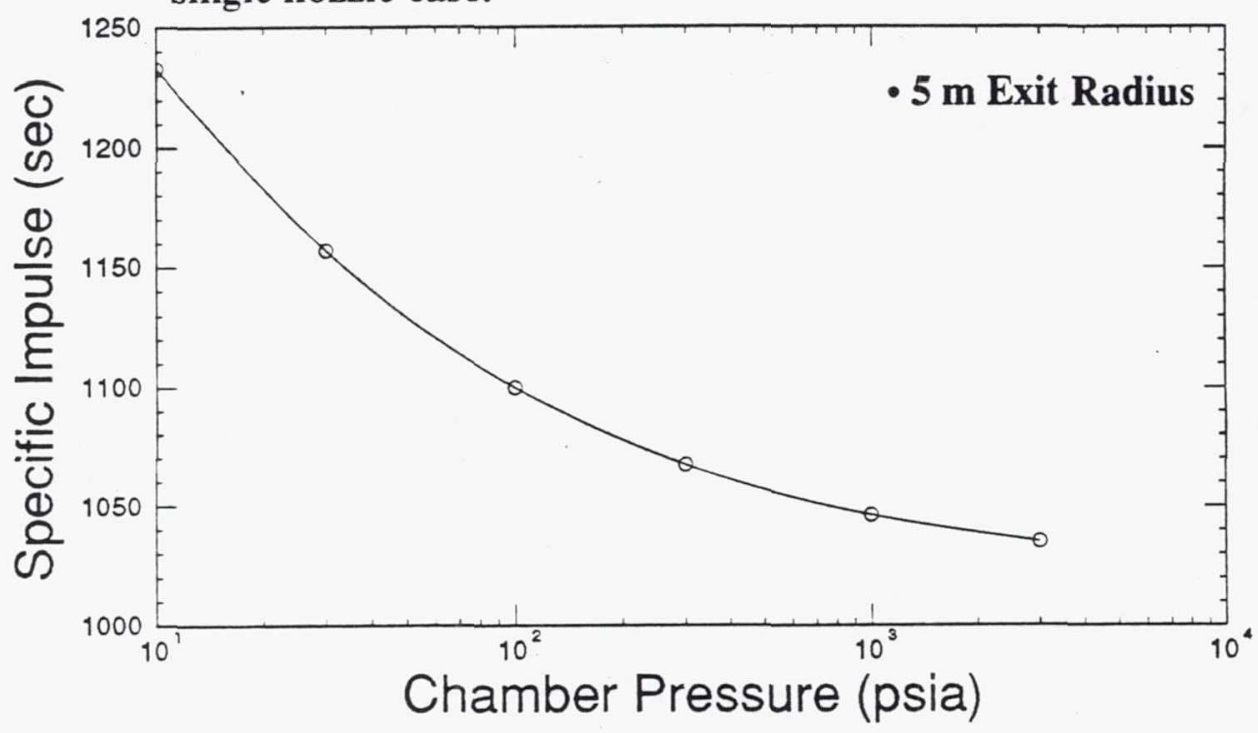

reaction rates were calculated with the OneDimensional Equilibrium (ODE) subprogram. Next, the one-dimensional finite chemical reaction rate performance predictions were computed with the One-Dimensional Kinetics (ODK) subprogram, followed by an inviscid Two-Dimensional Kinetics (TDK) subprogram calculations. Finally, the Boundary Layer Method (BLM) subprogram, with a final TDK run, was added to this series. The second pass of TDK calculated the nozzle performance in the boundary layer-displaced inviscid core. Therefore, $I_{s p}$ values were calculated by running the series of ODE, ODK, TDK, and TDK-BLM-TDK codes. When plotted together, the gaps between the curves labelled ODE and ODK, and between ODK and TDK show how chemical kinetic and two-dimensional effects vary as a function of chamber pressure, respectively. The gap between the TDK and the TDK-BLM-TDK curves show the variation of boundary layer losses with chamber pressure.

The two-dimensional chemical kinetic and boundary layer losses taken together are accurate. However, due to coupling of the twodimensional and boundary layer calculations, the isolated two-dimensional and boundary layer losses can only be considered approximate. Isolated boundary layer losses must be interpreted carefully since the TDK curves are plotted from data computed during the first TDK computational pass. The subsequent TDK pass, using a boundary layer displaced geometry, increases the inviscid core performance. To legitimately show the boundary layer drag losses as a function of chamber pressure, another curve would have to be plotted, based on the $I_{\text {sp }}$ calculated during the second pass of TDK in the TDK-BLM-TDK computational progression.

Infinite reaction rate $\mathrm{I}_{\mathrm{sp}}(\mathrm{ODE})$ specific impulse start very high at low chamber pressures and decreases as $\mathrm{p}_{c}$ increases. This is due to the increased levels of dissociated hydrogen in the chamber at lower chamber pressures, which contributes directly to the overall performance through the increased energy released when recombination occurs, and the performance also increases due to the decreased molecular weight of the propellant. As chamber pressure increases, the recombination of $\mathrm{H}$ into $\mathrm{H}_{2}$ decreases since the initial amount of disso- 
Figure 5. Specific impulse breakdown for $3100 \mathrm{~K}$ chamber temperature and $10 \mathrm{KJb}_{\mathrm{f}}$ thrust level, 1 nozzle with exit radius of 5 meters.

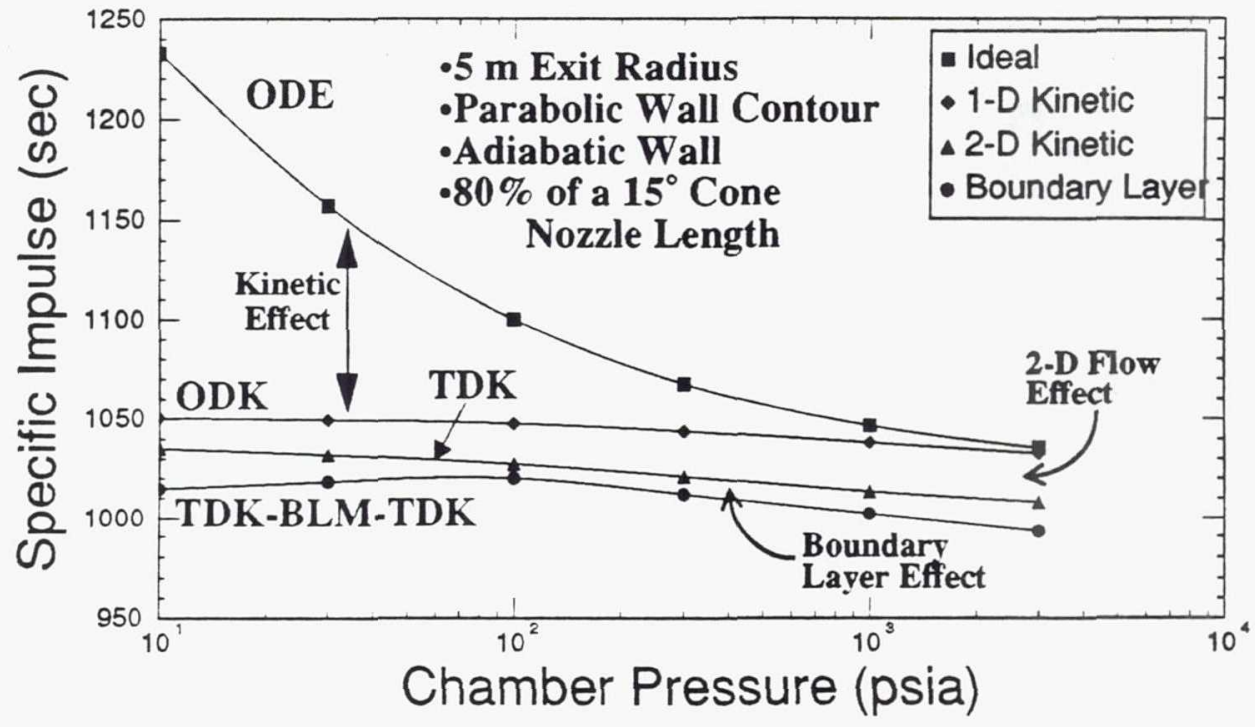

ciated hydrogen in the chamber is diminished at higher chamber pressures. Only in one case $\left(T_{c}=3100 \mathrm{~K}\right.$, and $\mathrm{F}=300,000 \mathrm{lb}_{\mathrm{f}}$, one nozzle, Figure A-16) does the equilibrium performance fail to follow the trend described above. This is due to the very large throat required to produce the desired thrust at the given chamber pressures. A large throat results in a lower area ratio $(<10: 1)$, which reduces the performance of the nozzle. In all other cases, nozzle area ratio was a secondary consideration compared to hydrogen recombination effects.

As can be seen in Figure 5, the ODE performance results are greater than the ODK values at all chamber pressures, although the difference is greatest at lower chamber pressures. Because of relatively slow chemical recombination at low chamber pressures, ODK perfor-

Figure 6. Decrements to $I_{s p}$ due to one-dimensional kinetic effects as a percentage of ODE performance for all operating conditions.

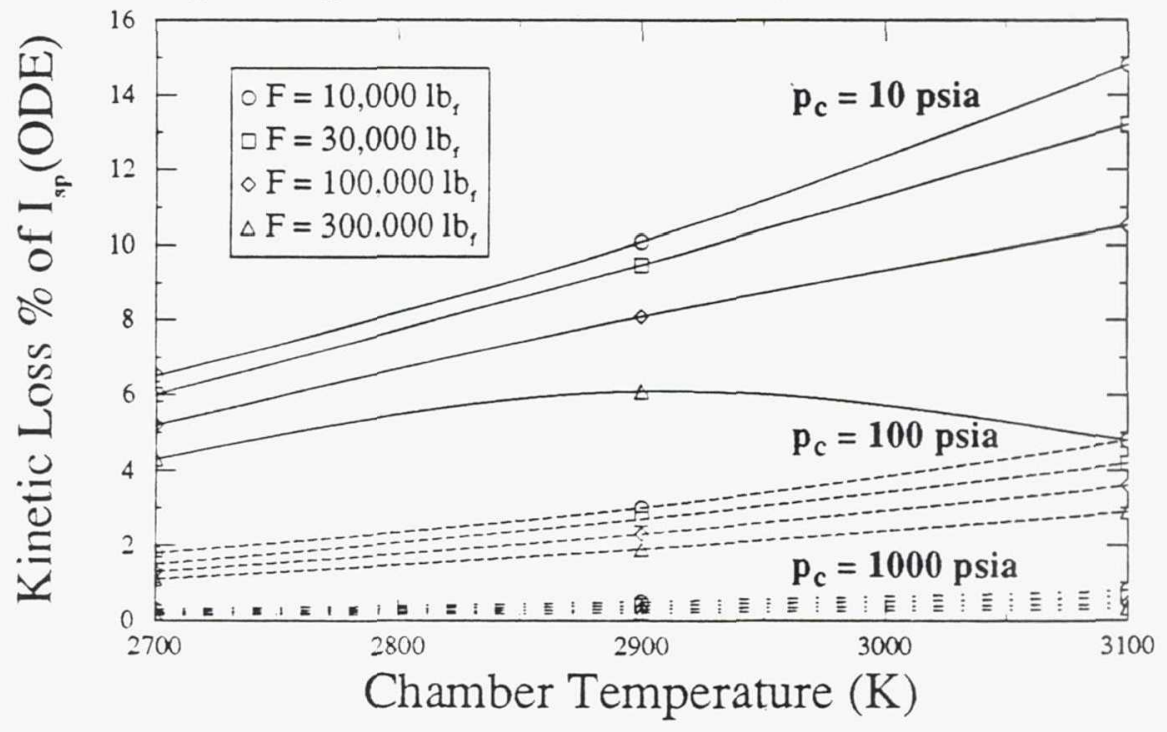


Figure 7. Kinetic performance efficiency $\left(\mathrm{I}_{\mathrm{sp}}(\mathrm{ODK})\right.$ divided by $I_{\text {sp }}(O D E)$ ) depicting kinetic losses for all operating conditions.

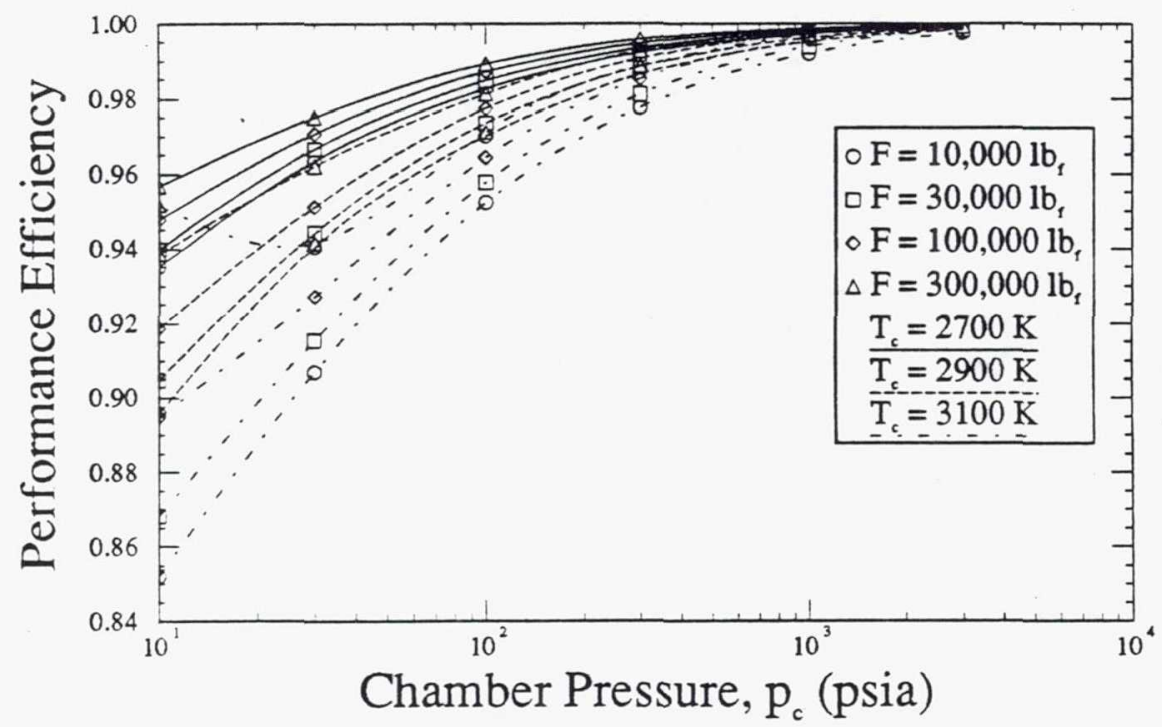

mance, $I_{\text {sp }}(O D K)$, is appreciably less than $I_{\text {sp }}(O D E)$. Figure 6 depicts the kinetic losses as a percentage of equilibrium $I_{\text {sp }}$. As chamber pressure increases, the ODE and ODK values converge in Figure 5, because as chamber pressure increases, the amount of $\mathrm{H}$ present is minimal and because recombination rates increase significantly as a function of pressure.
This trend is reflected in Figure 6 by the kinetic loss curves moving closer to the horizontal axis, which represents very small kinetic losses.

Kinetic losses of $15 \%$ occur at low chamber pressure "and thrust level, the precise operating conditions where the equilibrium specific impulse was predicted by ODE to be in excess of $1200 \mathrm{sec}$ (refer to Figures 4 or 5). This is the

Figure 8. Performance efficiency $\left(\mathrm{I}_{\mathrm{sp}}\right.$ (TDK-BLM-TDK) divided by $\mathrm{I}_{\mathrm{sp}}(\mathrm{ODE})$ ) depicting kinetic, two-dimensional, and boundary layer losses for all operating conditions.

Single nozzle case.

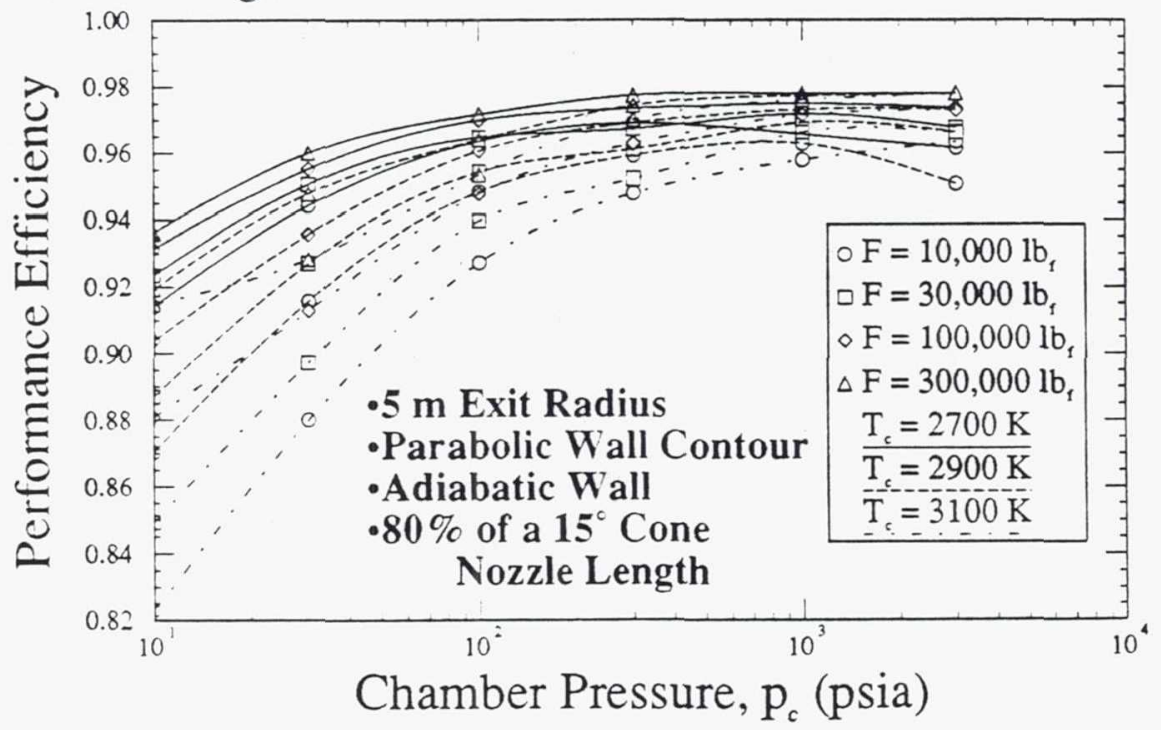


major reason why such high nozzle performance cannot be attained at these operating conditions.

Kinetic performance efficiency, defined as the $I_{s p}(O D K)$ divided by the $I_{s p}(O D E)$, is shown for the entire matrix of $\mathrm{p}_{c}, T_{c}$, and $F$ in Figure 7. As the extent of dissociated hydrogen present in the chamber increases monatomically with increasing chamber temperature, the overall trend of decreased performance efficiency with increasing chamber temperature would be expected, as shown in Figure 7.

Two-dimensional and boundary layer losses, as computed in the TDK-BLM-TDK sequence of analyses, account for the performance decrement between the curves labelled ODK and TDK-BLM-TDK in Figure 5.

Combined, the two-dimensional and boundary layer losses subtract between 1.5 and $3.5 \%$ from the $\mathrm{I}_{\mathrm{sp}}(\mathrm{ODE})$. Compared to a possible $15 \%$ loss due to kinetic effects, these losses seem minor. However, at high chamber pressures where kinetic effects are minimal, the $2 \%$ two-dimensional/boundary layer losses are the major contributor to performance degradation. Figure 8 shows the delivered performance efficiency, $\mathrm{I}_{\mathrm{sp}}$ (TDK-BLM-TDK) divided by
$\mathrm{I}_{\mathrm{sp}}(\mathrm{ODE})$, which includes the boundary layer and two-dimensional losses along with the kinetic losses. This figure indicates that at low pressure, low thrust level, and for an exit radius of 5 meters, a performance efficiency of 0.82 can be expected. This lowers the predicted Isp(ODE) of 1230 seconds to a delivered $\mathrm{I}_{\text {sp }}$ (TDK-BLM-TDK) of 1010 seconds.

The actual value of delivered $I_{s p}$ at each point provides the most important glimpse as to which parameters most affect the delivered nozzle performance of an NTR. Delivered $I_{s p}$ as a function of chamber pressure, for all chamber temperatures and thrust levels, is shown in Figure 9. From this figure, it can be seen that maximum deliverable $I_{\text {sp }}$ values range between 930 seconds for $a T_{c}$ of $2700 \mathrm{~K}$, to 1030 for a $T_{c}$ of $3100 \mathrm{~K}$.

Also from Figure 9, it can be seen that for every $200 \mathrm{~K}$ increase in $T_{c}$, a 40 to 50 second increase of delivered $\mathrm{I}_{\mathrm{sp}}$ results. At low chamber pressures, the thrust level can greatly affect the nozzle performance. Figure 9 also shows that, to get a maximum $I_{s p}$ value at low chamber pressures, a low thrust level (corresponding to high area ratios) would be desirable. For low chamber pressures, changing the

Figure 9. Delivered nozzle performance, including kinetic, twodimensional, and boundary layer losses of an NTR.

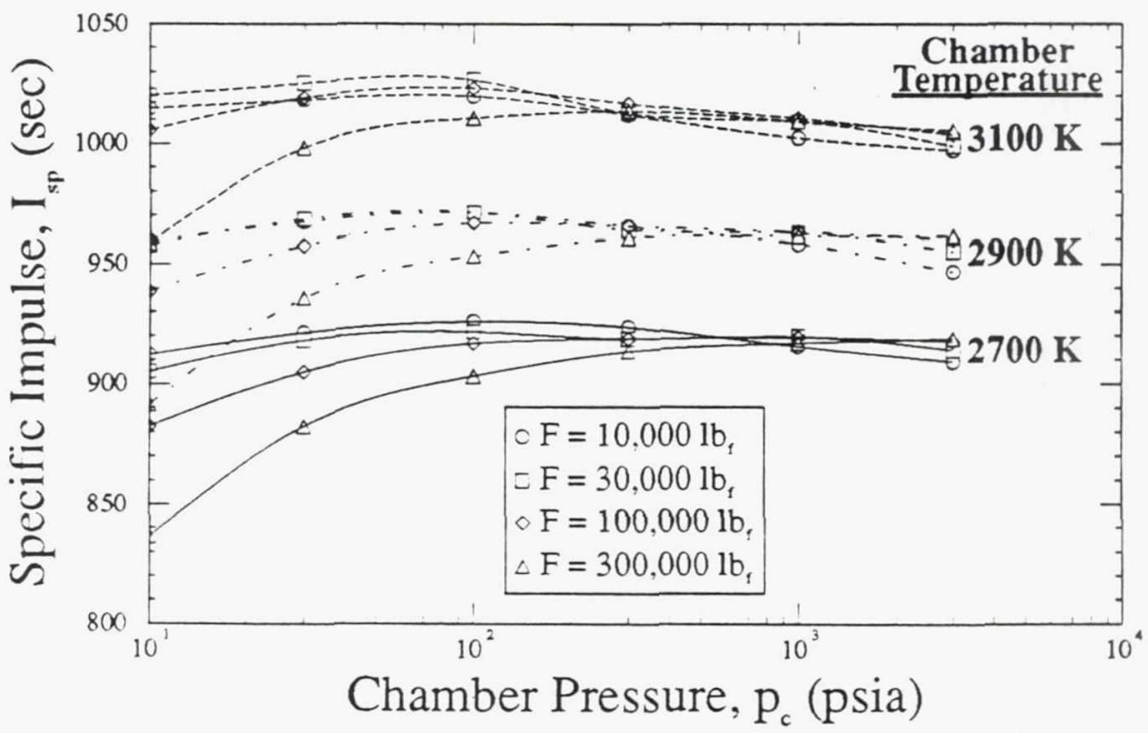


Figure 10. Cluster configurations of 3,5 , and 7 nozzles used in this study.

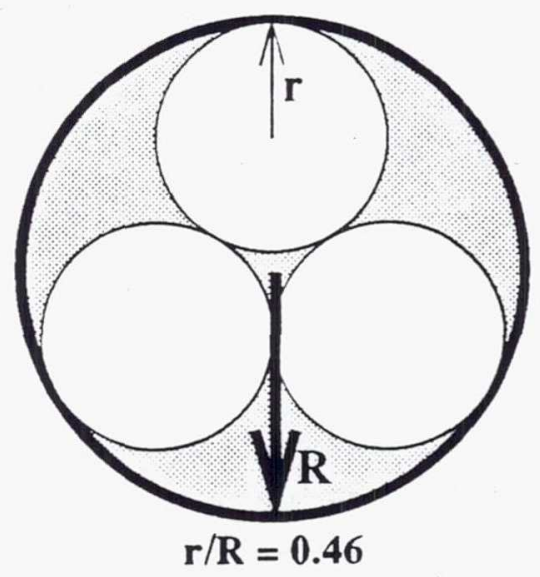

Area $=64 \%$ of 1 Nozzle

Three Nozzles

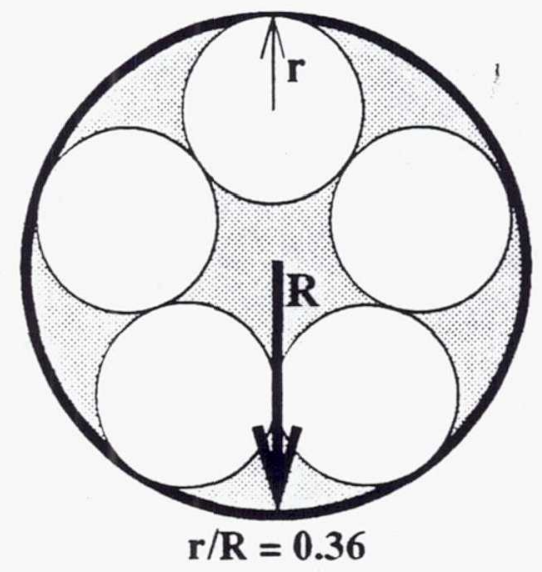

Area $=65 \%$ of 1 Nozzle

Five Nozzles

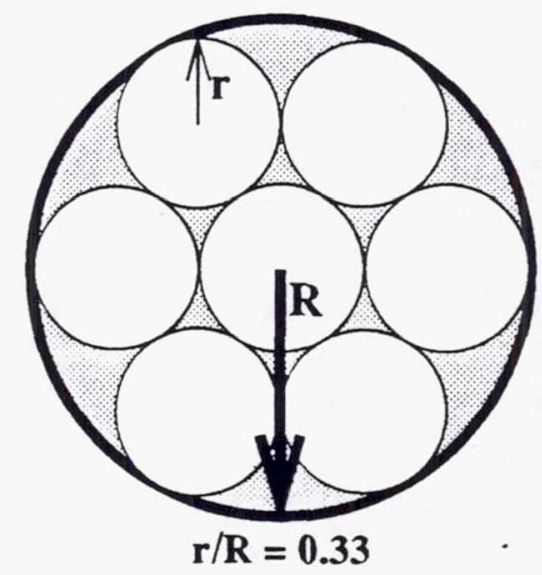

Area $=78 \%$ of 1 Nozzle

Seven Nozzles thrust level from 10,000 to $300,000 \mathrm{lb}_{\mathrm{f}}$ decreased performance by approximately 80 seconds. Higher performance at low thrust occurs because this condition corresponds to a high area ratio nozzle, which more than compensates for the reduced kinetic efficiency of a low thrust nozzle. However, at moderate to high chamber pressures $\left(p_{c}>100 \mathrm{psia}\right)$, the selection of thrust level has little effect on performance. This indicates that $I_{s p}$ at high $p_{c}$ is insensitive to area ratio variations.

\section{Multiple Nozzles}

An investigation into the effect of multiple nozzles on the performance and geometric parameters was conducted. Clusters of 1, 3, 5, and 7 nozzles which fit into the same five meter exit radius were investigated. Figure 10 shows the arrangement of each multiple nozzle configuration. Ratios of the single nozzle radius to the multiple nozzle radii, as well as the percentage of area coverage by the multiple nozzle configurations, are given. In the study, each configuration had an equal propulsion system thrust level.

For the most part, multiple nozzle clusters consisting of 3,5, or 7 nozzles performed between 1 to $2 \%$ ( 10 to 20 seconds of $I_{\text {sp }}$ ) below their single nozzle counterparts. In only a few cases (low chamber pressure and high thrust level for all chamber temperatures) did the performance penalty of going to multiple nozzles exceed $2 \%$ and reach approximately $4 \%$. Because of this, the resulting performance curves for multiple nozzles closely resembled those shown in Figure 9. Delivered performance for $T_{c}=3100 \mathrm{~K}$ and $\mathrm{F}=300 \mathrm{Klb}_{\mathrm{f}}$ is plotted for 1, 3, 5, and 7 nozzles in Figure 11. The relative insensitivity of nozzle performance to multiple nozzle configurations was expected because:

- boundary layer losses were shown to be small,

- two-dimensional losses are insensitive to chamber pressure and thrust levels, and

- little hydrogen recombination occurs beyond the throat.

All multiple nozzle curves are given in Appendix, Figures A-19 through A-72.

A benefit of the use of multiple nozzles is the geometric compactness of multiple nozzles as compared to single nozzle geometries. Figure 12 shows a comparison of nozzle lengths for 1, 3,5, and 7 nozzles. As the number of nozzles (engines) increases to attain a fixed thrust level, the amount of thrust per 
Figure 11. Effect of multiple nozzles on performance. Chamber temperature $=3100 \mathrm{~K}, 300,000 \mathrm{lb}_{\mathrm{f}}$ thrust case.

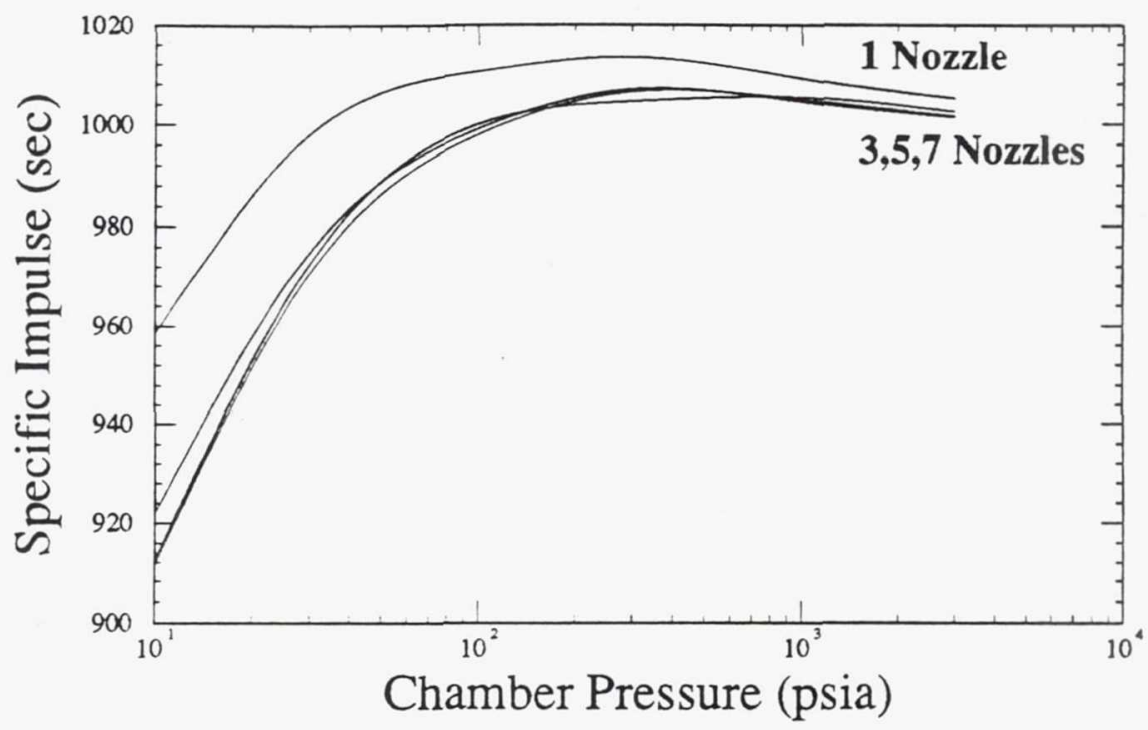

nozzle decreases, but so does the exit radius per nozzle. The throat radius computed to attain the target thrust level resulted in area ratio trends which follow the percentage of a single nozzle area trends (given in Figure 10). A 65\% reduction in nozzle length can be achieved by utilizing a five nozzle cluster instead of a single nozzle to produce the same thrust level. Gains attained by increasing the number of nozzles from 5 to 7 are less than $5 \%$. The results of Figure 12 combined with the finding that overall delivered performance remained roughly constant with the use of multiple nozzles indicates that substantial reductions in the overall nozzle package can be realized. Simplified analyses of nozzle weights (based only on surface area) indicate that mass savings of approximately $25 \%$ can be made for the cluster of five nozzles.

Therefore, although multiple nozzle configurations may decrease slightly the nozzle performance, it is clear that shorter nozzles can be designed by using a cluster of multiple nozzles which, in turn, permits packaging of the propulsion system into a smaller volume.

\section{Chemical Reaction Rates}

The chemical reaction rates used in this study (given in Table 3) were based on suggestions made by the National Aerospace Plane Rate Constant Committee of the NASP HighSpeed Propulsion Technology Team ${ }^{10}$.

Figure 12. The effect of multiple nozzles on overall nozzle length, expressed as a percentage of single nozzle length.

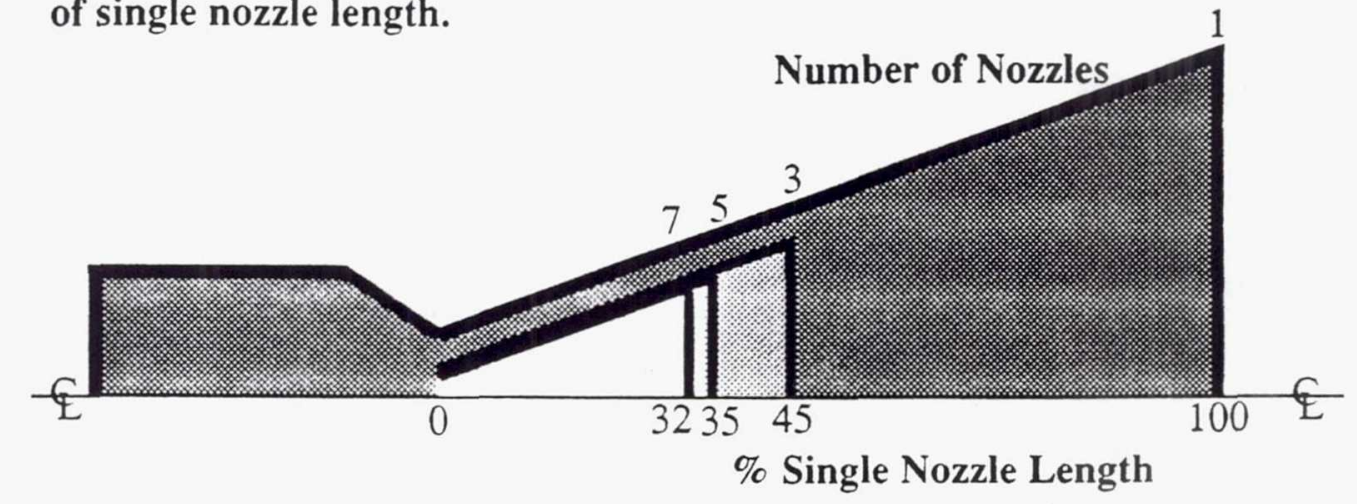


Table 3. Baseline reactions and rates.

\section{Reaction: Reaction Rate Equation}

$\mathrm{H}+\mathrm{H}+\mathrm{H}_{2} \rightarrow \mathrm{H}_{2}+\mathrm{H}_{2}$ with $k=1.8 \times 10^{18} T^{-1}$

$\mathrm{H}+\mathrm{H}+\mathrm{H} \rightarrow \mathrm{H}_{2}+\mathrm{H}$ with $k=1.5 \times 10^{19} \mathrm{~T}^{-1}$

A sensitivity study of the effect of chemical reaction rate on specific impulse was performed. Chemical reaction rates are calculated in the TDK program by the Ahrennius equation,

$$
k=A T^{-n} e^{-\left(\frac{1000 b}{R T}\right)}
$$

where $k$ is the reaction rate, $A, b$, and $n$ are rate constants, $T$ is the reaction temperature, and $R$ is the specific gas constant. To determine sensitivity of the results to the reaction rate constant values, a series of computer runs were performed for the $100,000 \mathrm{lb}_{\mathrm{f}}$ thrust level, the $2900 \mathrm{~K}$ chamber temperature, and the single nozzle case. Reactions which were an order of magnitude slower and faster than the baseline reaction rates were input and the performance was calculated using the ODE-ODK program sequence to determine the effect of reaction rate variation on kinetic losses. The uncertainty in $\mathrm{H}$ recombination rates is currently thought to be between a factor of 2 and $4 .{ }^{107}$ By varying the baseline reaction rates by an extreme factor of uncertainty, 10, and recomputing the NTR nozzle performance at one set of operating conditions, the change in specific impulse for an order of magnitude change in reaction rate was determined. Results are shown in Figure 13.

For chemical reactions which were a factor of 10 slower than the NASP suggested rates, $\mathrm{I}_{\mathrm{sp}}$ values were approximately 10 seconds (1\%) lower for chamber pressures under 300 psia. Above 300 psia, the effect of slowing down the reaction rates seemed to diminish.

For chemical reactions which were a factor of 10 faster than the suggested rates, the trend of $I_{s p}$ was approximately the same as for the slower reactions. An increase of approximately 20 seconds $(2 \%)$ was seen in the cases where chamber pressure is less than $300 \mathrm{psia}$. In the 300 psia case and above, however, a smaller increase in performance was predicted. This is due to nearly negligible kinetic losses at high chamber pressures. Overall, the influence of chemical reaction rates at all chamber pressures is secondary, causing a maximum variation of approximately $2 \%$.

Figure 13. Effect of recombination rate variation on NTR nozzle performance. Chamber temperature is $T_{c}=2900 \mathrm{~K}$, $\mathrm{F}=100 \mathrm{Klb}_{\mathrm{f}}$, single nozzle case.

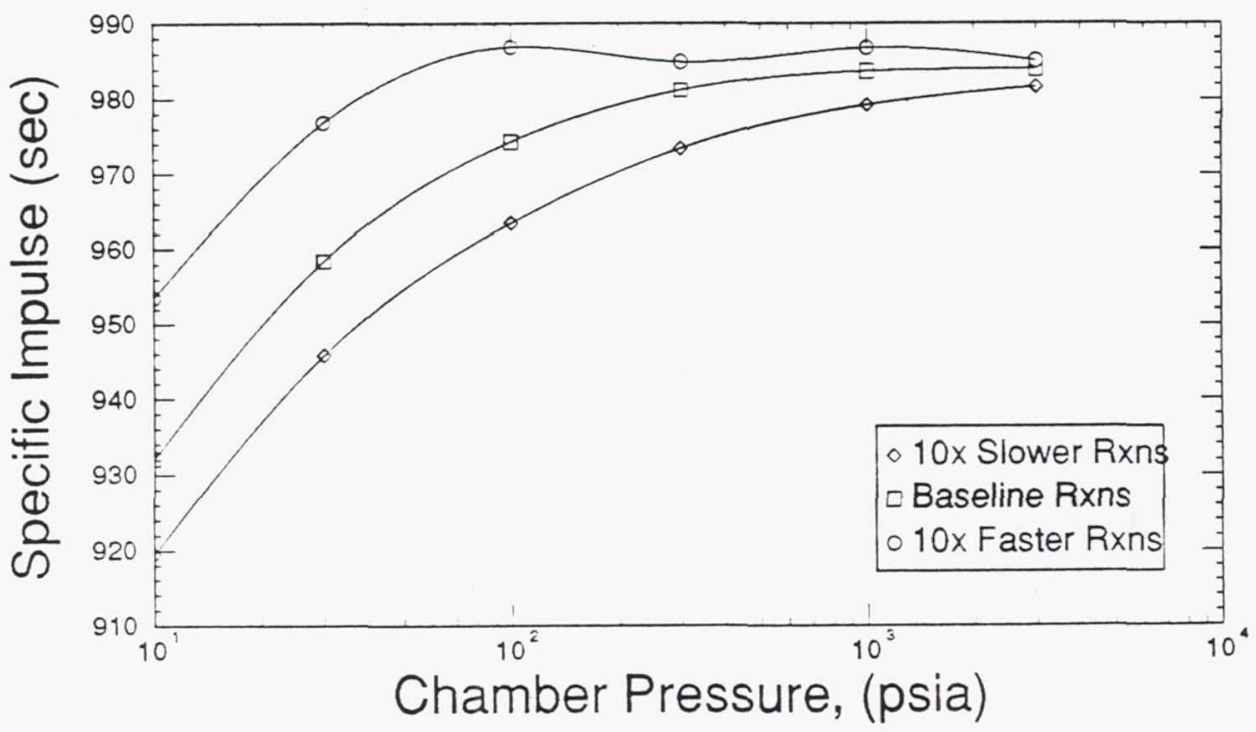




\section{Summary of Results}

Nozzle performance of a Nuclear Thermal Rocket was calculated over a range of chamber pressures, chamber temperatures, and thrust levels. NTR performance delivered by clusters of multiple nozzles were also considered.

Recombination of monatomic hydrogen to diatomic hydrogen was investigated. Results show that a majority of the recombination process occurs in the near-throat region.

Nozzle lengths at low $p_{c}$ levels are very sensitive to thrust level. Nozzle lengths for higher thrust levels are shorter than those for lower thrust levels, because of the lower area ratios for the high thrust nozzles. As $p_{c}$ increases, nozzle lengths for all thrust levels in different multiple nozzle configurations asymptotically approach lengths of $3 r_{c}$ (1 nozzle), $1.4 \mathrm{r}_{e}$ (3 nozzles), $1.1 \mathrm{r}_{\mathrm{e}}$ (5 nozzles), and $\mathrm{r}_{e}$ (7 nozzles).

Although one-dimensional, infinite reaction rate performance predictions can exceed 1200 seconds at low pressure and low thrust levels, kinetic effects on $I_{s p}$ can decrement the equilibrium value by up to $15 \%$.

Kinetic losses are minimized in the high $\mathrm{p}_{c}$ regime. Two-dimensional and boundary losses combine to produce a relatively constant $2 \% \mathrm{I}_{\mathrm{sp}}$ decrement for all $p_{c}$ and $F$. Maximum $I_{s p}$ values range between 930 seconds at $T_{c}$ of $2700 \mathrm{~K}$ to 1030 seconds at $T_{c}$ of $3100 \mathrm{~K}$.

Although they deliver the same amount of thrust, multiple nozzle configurations underperform their single nozzle counterpart by between 2 to $4 \%$ due to a decrease in area ratio and kinetic efficiency of each nozzle. However, the length of each nozzle in the cluster is shorter than the single nozzle length. A $65 \%$ nozzle length reductions can be achieved by a 5 nozzle cluster as compared to a single nozzle delivering the same thrust level.

An order of magnitude variation in the rates of the recombination reactions can cause performance decrements or increases of less than $2 \%$.

\section{Concluding Remarks}

Geometric parameters which describe the near-throat region of the convergent-divergent nozzle were selected to be representative of a chemical rocket engine. The effect of these parameters on NTR nozzle performance was not investigated, but the results of this study indicate that hydrogen recombination is largely limited to the near throat region. Sensitivity studies of all these parameters would help to maximize the recombination of $\mathrm{H}$ to $\mathrm{H}_{2}$, maximizing the energy release and delivered performance of an NTR nozzle.

Other assumptions which were made to describe the nozzle geometry may have an effect on $\mathrm{I}_{\mathrm{sp}}$ if they were changed. For example, the parabolic nozzle contour was not optimized according to known methods. Although nozzle performance was shown to be insensitive to area ratio at high chamber pressures, extrapolation of these results for a nozzle with exit radius of 1 meter instead of 5 meters might not provide accurate results. Nozzle lengths, assumed to be $80 \%$ of a $15^{\circ}$ cone, may be substantially longer in reality for the high area ratio regimes. Finally, approximations were used to calculate the geometric variations due to multiple nozzle clusters. Differences may result from using realistic values to account for spacing between adjacent nozzles, etc.

Boundary layer assumptions made were felt to be realistic and could be approximated in an actual nozzle. However, the sensitivity of nozzle performance to wall temperature needs to be investigated.

Results of this study which may have impact on previous or existing studies or programs include:

- no performance benefit can be expected from low chamber pressure for the design constraints used in this study (refer to Figure 9),

- results matched presented NERVA derivative reactor (NDR) per- 
formance data, where the operating conditions were $T_{c}=2700 \mathrm{~K}$, $\mathrm{p}_{\mathrm{c}}=1000$ psia, $\mathrm{F}=75,000 \mathrm{lb}_{\mathrm{f}}$, area ratio $=500: 1$ had a predicted performance of 925 seconds, compared to this study's $T_{c}=2700 \mathrm{~K}$, $\mathrm{P}_{\mathrm{c}}=1000 \mathrm{psia}, \mathrm{F}=100,000 \mathrm{lb}_{\mathrm{f}}$, area ratio $=463: 1$ predicted performance of 915 seconds, and

- the maximum attainable specific impulse for a chamber temperature of $3100 \mathrm{~K}$ is approximately 1030 seconds, for $\mathrm{T}_{c}$ of $2900 \mathrm{~K}$, maximum performance is approximately 970 seconds, and for $T_{c}$ of $2700 \mathrm{~K}$, maximum performance is approximately 930 seconds.

\section{References}

1. Bennett, Gary L., "Nuclear Thermal Propulsion Program Overview", presentation given at the Nuclear Thermal Propulsion Workshop held at NASA Lewis Research Center, 10 July 1990.

2. Parsley, R.C., et. al., "A Low Thrust Near Term Nuclear Thermal Rocket Concept", AIAA-91-3352, American Institute of Aeronautics and Astronautics (1991).

3. Clark, J.S., "A Comparison of Nuclear Thermal Propulsion Concepts: Results of a Workshop", Proceedings of the Eighth Symposium on Space Nuclear Power Systems, CONF-910116, held in Albuquerque, New Mexico, 6-10 January 1991.

4. Borowski, S.K., "The Rationale/Benefits of Nuclear Thermal Rocket Propulsion for NASA's Lunar Space Transportation System", AIAA-91-2052, American Institute of Aeronautics and Astronautics (1991).

5. Davidian, Ken, “A Rocket Engine Design Expert System”, NASA TM-102373, October 1989 .
6. Davidian, Ken, "Developments in REDES: The Rocket Engine Design Expert System", NASA TM-103657, November 1990.

7. "JANNAF Rocket Engine Performance Prediction and Evaluation Manual", CPLAPUBL-245, Chemical Propulsion Information Agency, Laurel, MD, April, 1975.

8. Nickerson, G.R., Coats, D.E., and Dang, L.D., "Two Dimensional Kinetic Reference Computer Program, (TDK)" NASA CR17828, 1985.

9. Huzel, Dieter K., and Huang, David H., "Design of Liquid Propellant Rocket Engines", NASA SP-125, 1967.

10. Personal communication with Richard Oldenborg, Los Alamos National Laboratory, 8 March 1991. 


\section{APPENDIX}

\section{FIGURES OF PARAMETRIC DATA}

The figures on the following pages graphically present the results of the computational study described in the report. Figures are grouped into sets of six plots: four specific impulse versus chamber pressure plots (one for each thrust level), one area ratio versus chamber pressure plot, and one nozzle length versus chamber pressure plot. Each of these six plots are repeated for each chamber temperature (three) and each multiple nozzle configuration (four). All curves are for the single nozzle configuration unless otherwise noted.

\section{Fig Description}

A-1 $T_{c}=2700 \mathrm{~K} \mathrm{~F}=10 \mathrm{Klb}_{\mathrm{f}} 1$ Nozzle

A-2 $T_{c}=2700 \mathrm{~K} \mathrm{~F}=30 \mathrm{Klb}_{\mathrm{f}} 1$ Nozzle

Page

A-3 $T_{c}=2700 \mathrm{~K} \mathrm{~F}=100 \mathrm{Klb}_{\mathrm{f}} 1$ Nozzle

A-4 $T_{c}=2700 \mathrm{~K} \mathrm{~F}=300 \mathrm{Klb}_{f} 1$ Nozzle ........16

A-5 $T_{c}=2700 \mathrm{~K}$ Area Ratio 1 Nozzle ........16

A-6 $T_{c}=2700 \mathrm{~K}$ Nozzle Length 1 Nozzle .. 16

A-7 $T_{c}=2900 \mathrm{~K} \mathrm{~F}=10 \mathrm{Klb}_{\mathrm{f}} 1$ Nozzle ...........17

A-8 $\quad T_{c}=2900 \mathrm{~K} \mathrm{~F}=30 \mathrm{Klb}_{\mathrm{f}} 1$ Nozzle ..........17

A-9 $\quad T_{c}=2900 \mathrm{~K} \mathrm{~F}=100 \mathrm{Klb}_{\mathrm{f}} 1$ Nozzle ….....17

A-10 $T_{c}=2900 \mathrm{~K} \mathrm{~F}=300 \mathrm{Klb}_{\mathrm{f}} 1$ Nozzle ….....17

A-11 $T_{c}=2900 \mathrm{~K}$ Area Ratio 1 Nozzle ........17

A-12 $T_{c}=2900 \mathrm{~K}$ Nozzle Length 1 Nozzle ..17

A-13 $T_{c}=3100 \mathrm{~K} \mathrm{~F}=10 \mathrm{Klb}_{\mathrm{f}} 1$ Nozzle ….......18

A-14 $T_{c}=3100 \mathrm{~K} \mathrm{~F}=30 \mathrm{Klb}_{\mathrm{f}} 1$ Nozzle …......18

A-15 $\quad T_{c}=3100 \mathrm{~K} \mathrm{~F}=100 \mathrm{Klb}_{\mathrm{f}} 1$ Nozzle ….....18

A-16 $T_{c}=3100 \mathrm{~K} \mathrm{~F}=300 \mathrm{Klb}_{\mathrm{f}} 1$ Nozzle ........18

A-17 $T_{c}=3100 \mathrm{~K}$ Area Ratio 1 Nozzle ….....18

A-18 $T_{c}=3100 \mathrm{~K}$ Nozzle Length 1 Nozzle. .18

A-19 $T_{c}=2700 \mathrm{~K} \mathrm{~F}=10 \mathrm{Klb}_{\mathrm{f}} 3$ Nozzles.........19

A-20 $T_{c}=2700 \mathrm{~K} \mathrm{~F}=30 \mathrm{Klb}_{\mathrm{f}} 3$ Nozzles.........19

A-21 $T_{c}=2700 \mathrm{~K} \mathrm{~F}=100 \mathrm{Klb}_{\mathrm{f}} 3$ Nozzles.......19

A-22 $T_{c}=2700 \mathrm{~K} \mathrm{~F}=300 \mathrm{Klb}_{\mathrm{f}} 3$ Nozzles ........19

A-23 $T_{c}=2700 \mathrm{~K}$ Area Ratio 3 Nozzles.......19

A-24 $T_{c}=2700 \mathrm{~K}$ Nozzle Length 3 Nozzles. 19

A-25 $T_{c}=2900 \mathrm{~K} \mathrm{~F}=10 \mathrm{Klb}_{\mathrm{f}} 3$ Nozzles.........20

A-26 $T_{c}=2900 \mathrm{~K} \mathrm{~F}=30 \mathrm{Klb}_{\mathrm{f}} 3$ Nozzles .........20

A-27 $T_{c}=2900 \mathrm{~K} \mathrm{~F}=100 \mathrm{Klb}_{\mathrm{f}} 3$ Nozzles .......20

A-28 $T_{c}=2900 \mathrm{~K} \mathrm{~F}=300 \mathrm{Klb}_{\mathrm{f}} 3$ Nozzles.......20

A-29 $T_{c}=2900 \mathrm{~K}$ Area Ratio 3 Nozzles.......20

A-30 $T_{c}=2900 \mathrm{~K}$ Nozzle Length 3 Nozzles. 20

A-31 $T_{c}=3100 \mathrm{~K} \mathrm{~F}=10 \mathrm{Klb}_{\mathrm{f}} 3$ Nozzles .........21

A-32 $T_{c}=3100 \mathrm{~K} \mathrm{~F}=30 \mathrm{Klb}_{\mathrm{f}} 3$ Nozzles.........21

A-33 $T_{c}=3100 \mathrm{~K} \mathrm{~F}=100 \mathrm{Klb}_{\mathrm{f}} 3$ Nozzles .......21

A-34 $T_{c}=3100 \mathrm{~K} \mathrm{~F}=300 \mathrm{Klb}_{\mathrm{f}} 3$ Nozzles .......21

A-35 $T_{c}=3100 \mathrm{~K}$ Area Ratio 3 Nozzles.......21

A-36 $T_{c}=3100 \mathrm{~K}$ Nozzle Length 3 Nozzles. 21
Fig Description

Page

A-37 $T_{c}=2700 \mathrm{~K} \mathrm{~F}=10 \mathrm{Klb}_{\mathrm{f}} 5$ Nozzles.........22

A-38 $\mathrm{T}_{\mathrm{c}}=2700 \mathrm{~K} \mathrm{~F}=30 \mathrm{Klb}_{\mathrm{f}} 5$ Nozzles.........22

A-39 $T_{c}=2700 \mathrm{~K} \mathrm{~F}=100 \mathrm{Klb}_{\mathrm{f}} 5$ Nozzles.......22

A-40 $T_{c}=2700 \mathrm{~K} \mathrm{~F}=300 \mathrm{Klb}_{\mathrm{f}} 5$ Nozzles.......22 $^{2}$

A-41 $T_{c}=2700 \mathrm{~K}$ Area Ratio 5 Nozzles.......22

A-42 $T_{c}=2700 \mathrm{~K}$ Nozzle Length 5 Nozzles 22

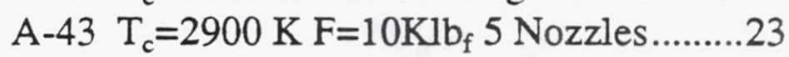

A-44 $T_{c}=2900 \mathrm{~K} \mathrm{~F}=30 \mathrm{Klb}_{\mathrm{f}} 5$ Nozzles.........23

A-45 $\mathrm{T}_{\mathrm{c}}=2900 \mathrm{~K} \mathrm{~F}=100 \mathrm{Klb}_{\mathrm{f}} 5$ Nozzles.......23

A-46 $T_{c}=2900 \mathrm{~K} \mathrm{~F}=300 \mathrm{Klb}_{\mathrm{f}} 5$ Nozzles.......23

A-47 $T_{c}=2900 \mathrm{~K}$ Area Ratio 5 Nozzles.......23

A-48 $T_{c}=2900 \mathrm{~K}$ Nozzle Length 5 Nozzles 23

A-49 $T_{c}=3100 \mathrm{~K} \mathrm{~F}=10 \mathrm{Klb}_{\mathrm{f}} 5$ Nozzles.........24

A-50 $T_{c}=3100 \mathrm{~K} \mathrm{~F}=30 \mathrm{Klb}_{\mathrm{f}} 5$ Nozzles.........24

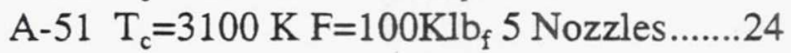

A-52 $T_{c}=3100 \mathrm{~K} \mathrm{~F}=300 \mathrm{Klb}_{\mathrm{f}} 5$ Nozzles.......24

A-53 $T_{c}=3100 \mathrm{~K}$ Area Ratio 5 Nozzles.......24

A-54 $T_{c}=3100 \mathrm{~K}$ Nozzle Length 5 Nozzles 24

A-55 $T_{c}=2700 \mathrm{~K} \mathrm{~F}=10 \mathrm{Klb}_{\mathrm{f}} 7$ Nozzles.........25

A-56 $T_{c}=2700 \mathrm{~K} \mathrm{~F}=30 \mathrm{Klb}_{\mathrm{f}} 7$ Nozzles.........25

A-57 $T_{c}=2700 \mathrm{~K} \mathrm{~F}=100 \mathrm{Klb}_{\mathrm{f}} 7$ Nozzles.......25

A-58 $T_{c}=2700 \mathrm{~K} \mathrm{~F}=300 \mathrm{Klb}_{\mathrm{f}} 7$ Nozzles.......25

A-59 $T_{c}=2700 \mathrm{~K}$ Area Ratio 7 Nozzzles.......25

A-60 $T_{c}=2700 \mathrm{~K}$ Nozzle Length 7 Nozzles 25

A-61 $T_{c}=2900 \mathrm{~K} \mathrm{~F}=10 \mathrm{Klb}_{\mathrm{f}} 7$ Nozzles.........26

A-62 $T_{c}=2900 \mathrm{~K} \mathrm{~F}=30 \mathrm{Klb}_{\mathrm{f}} 7$ Nozzles..........26

A-63 $T_{c}=2900 \mathrm{~K} \mathrm{~F}=100 \mathrm{Klb}_{\mathrm{f}} 7$ Nozzles.......26

A-64 $T_{c}=2900 \mathrm{~K} \mathrm{~F}=300 \mathrm{Klb}_{\mathrm{f}} 7$ Nozzles.......26

A-65 $T_{c}=2900 \mathrm{~K}$ Area Ratio 7 Nozzles.......26

A-66 $T_{c}=2900 \mathrm{~K}$ Nozzle Length 7 Nozzles 26

A-67 $T_{c}=3100 \mathrm{~K} \mathrm{~F}=10 \mathrm{Klb}_{\mathrm{f}} 7$ Nozzles.........27

A-68 $T_{c}=3100 \mathrm{~K} \mathrm{~F}=30 \mathrm{Klb}_{\mathrm{f}} 7$ Nozzles.........27

A-69 $T_{c}=3100 \mathrm{~K} \mathrm{~F}=100 \mathrm{Klb}_{\mathrm{f}} 7$ Nozzles.......27

A-70 $T_{c}=3100 \mathrm{~K} \mathrm{~F}=300 \mathrm{Klb}_{\mathrm{f}} 7$ Nozzles.......27

A-71 $T_{c}=3100 \mathrm{~K}$ Area Ratio 7 Nozzles.......27

A-72 $T_{c}=3100 \mathrm{~K}$ Nozzle Length 7 Nozzles 27 

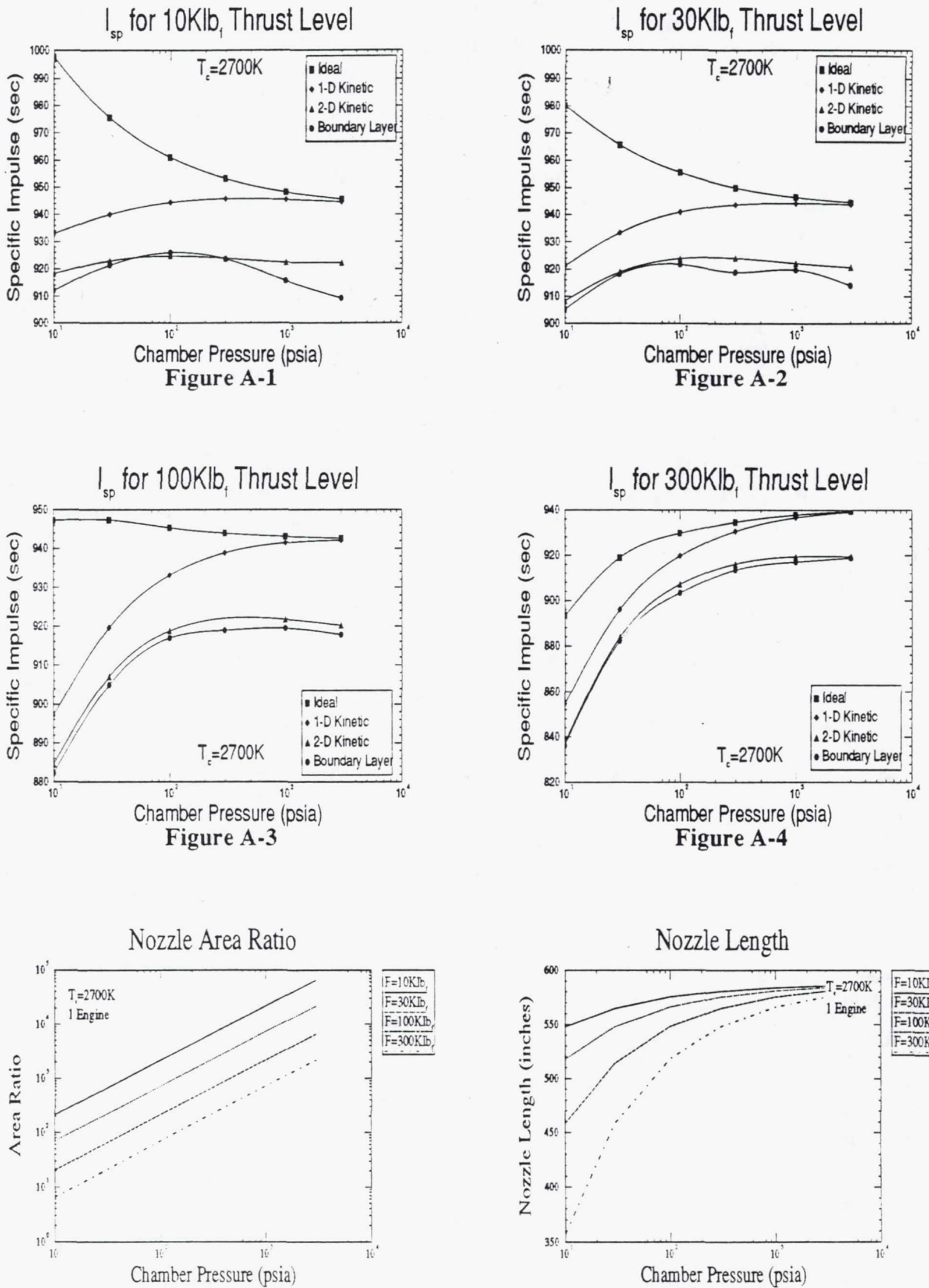

Figure A-5

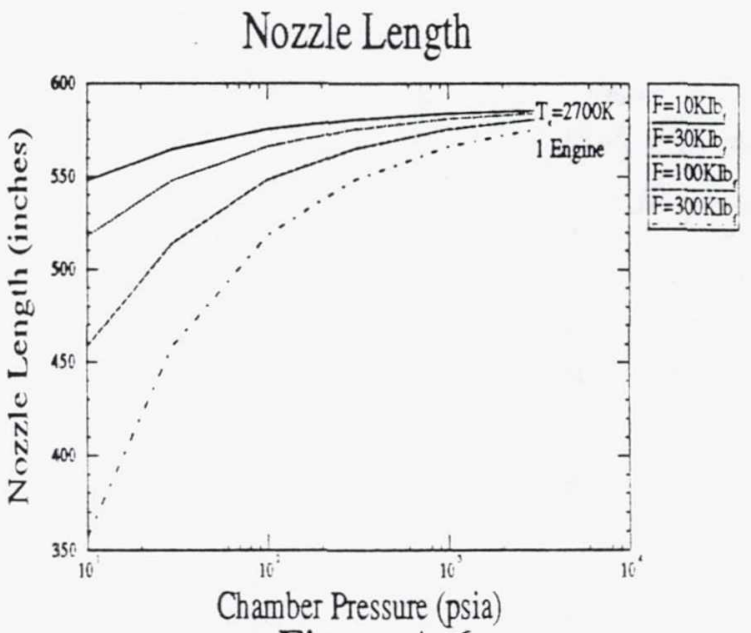

Figure A-6 

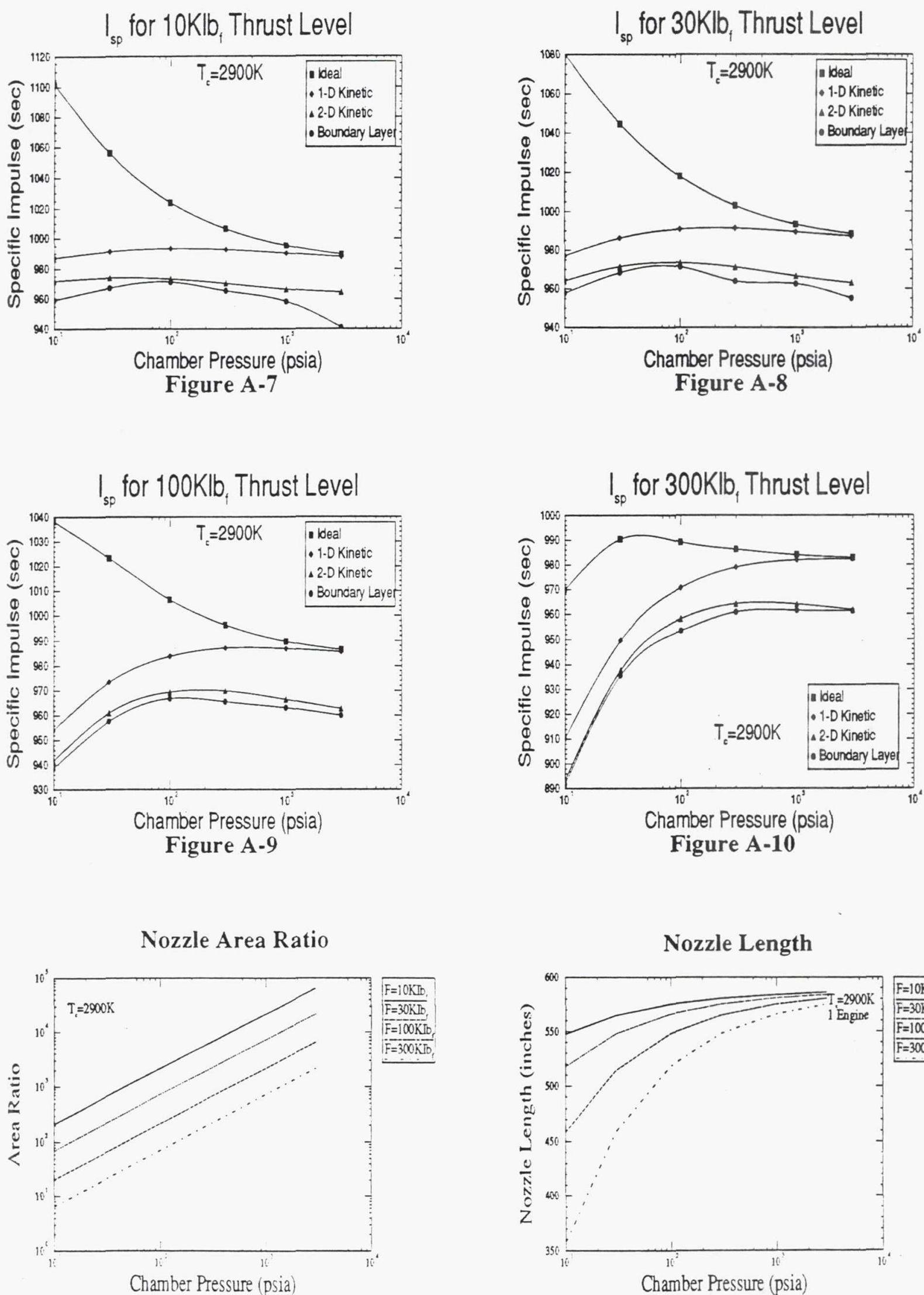

Figure A-11

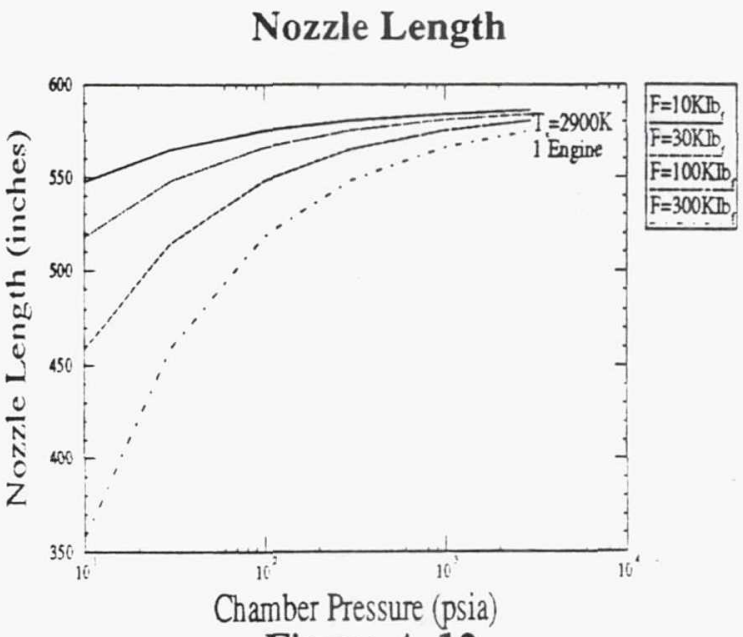

Figure A-12 


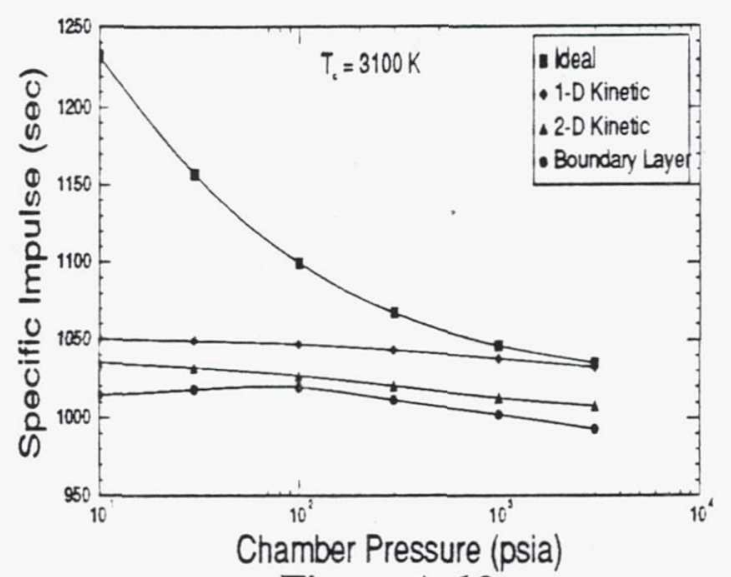

Figure A-13

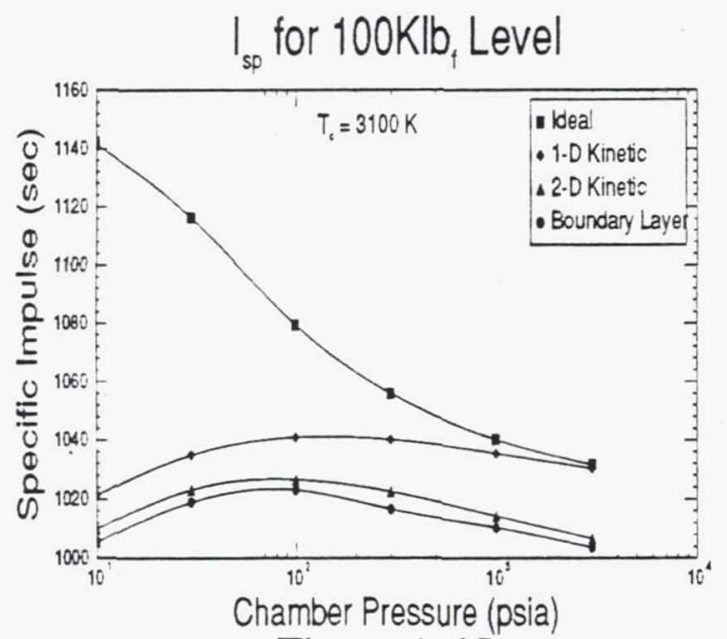

Figure A-15

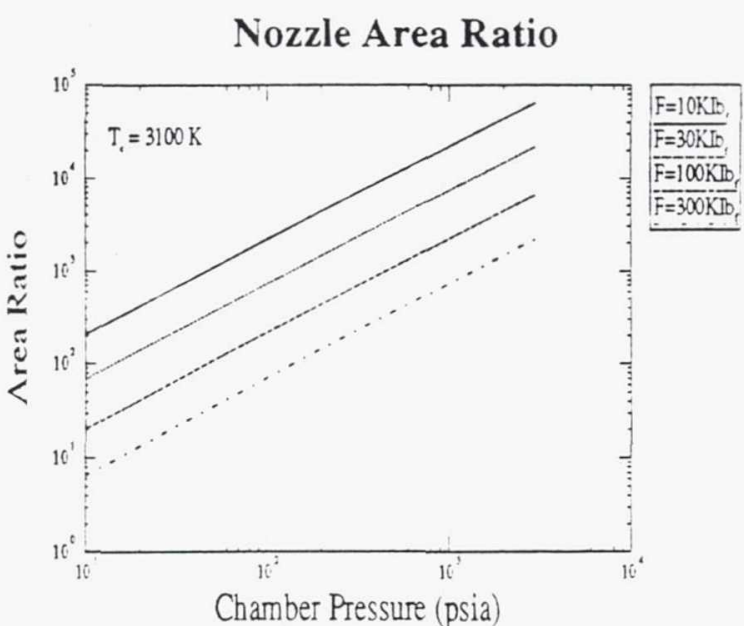

Figure A-17
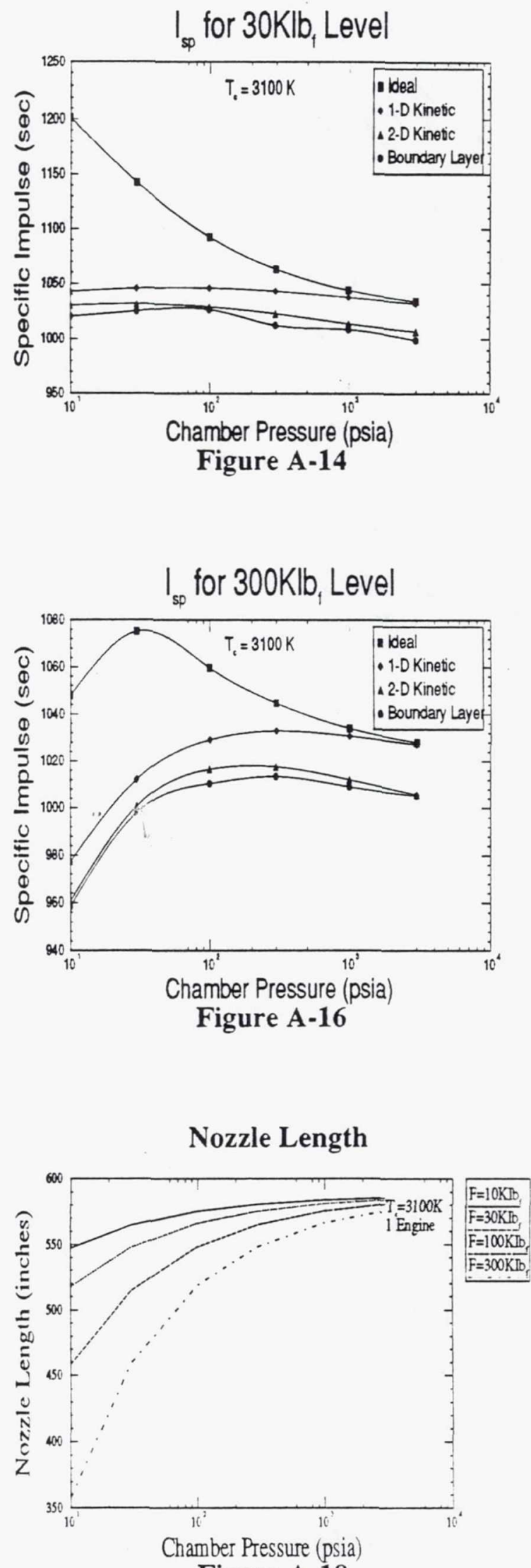

Figure A-18 


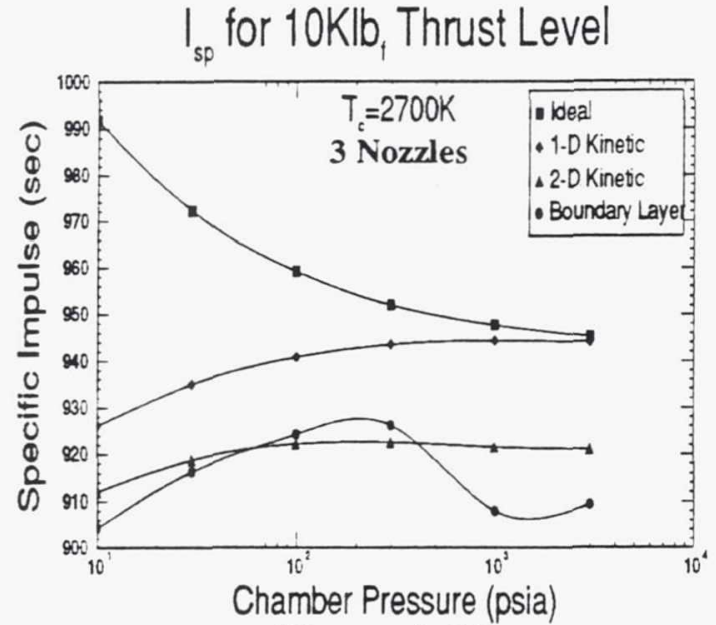

Figure A-19
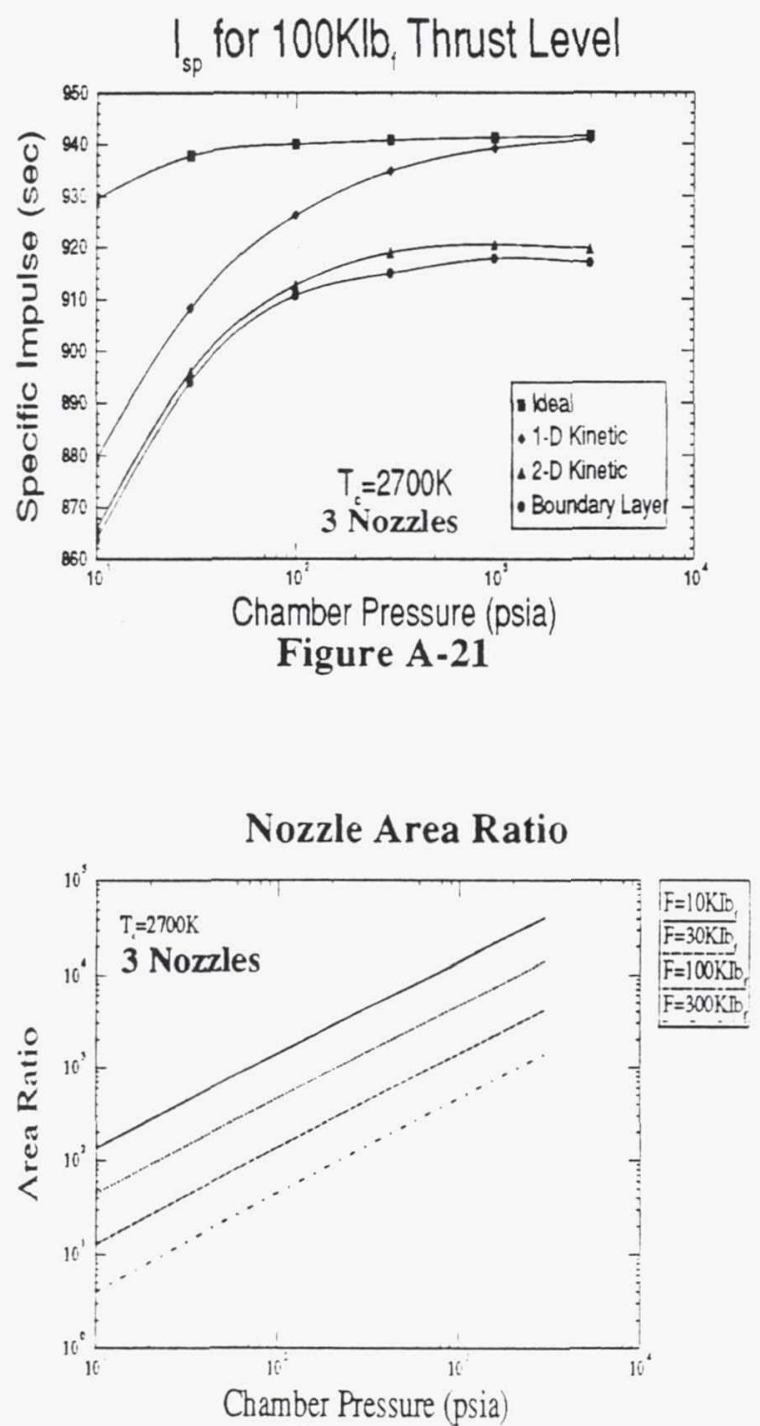

Figure A-23

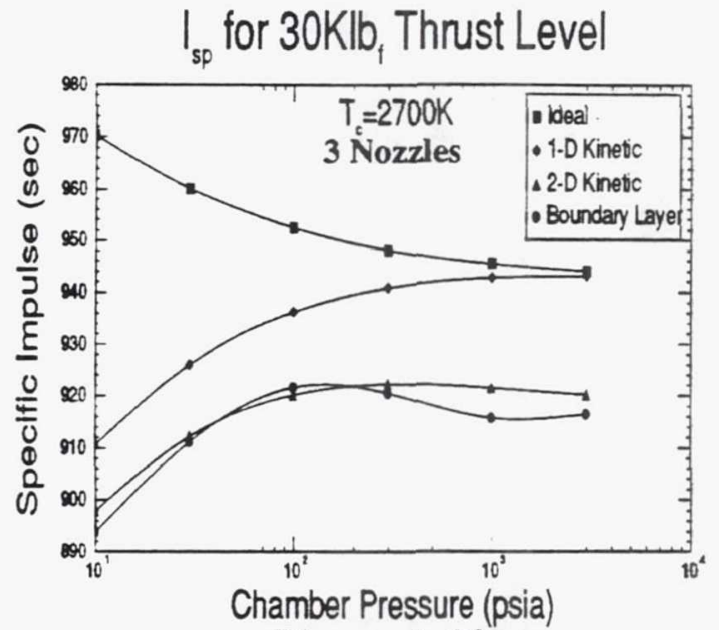

Figure A-20

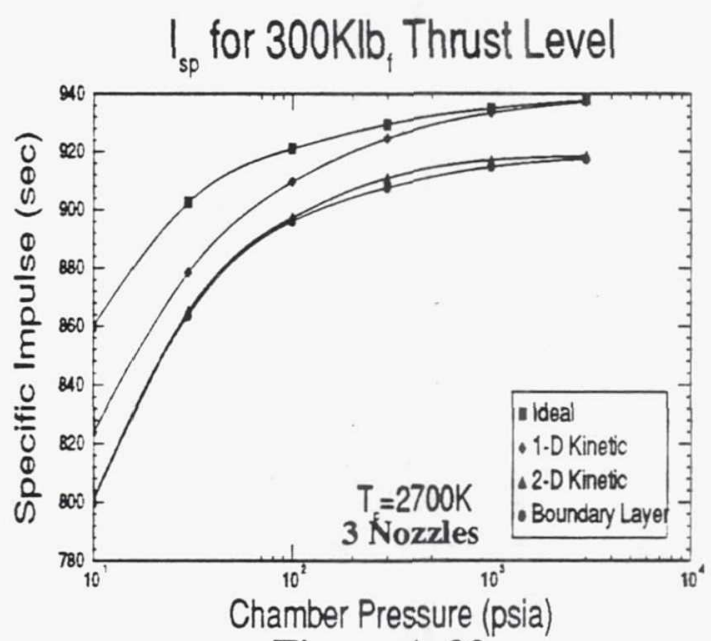

Figure A-22

\section{Nozzle Length}

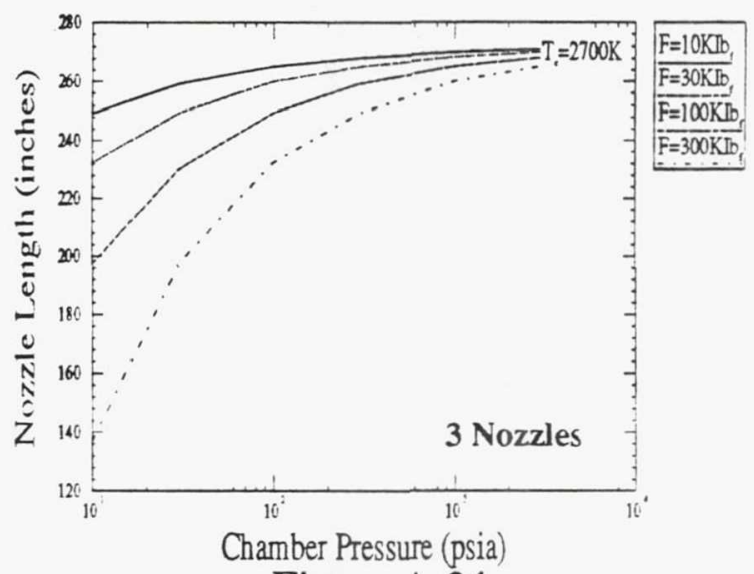

Figure A-24 


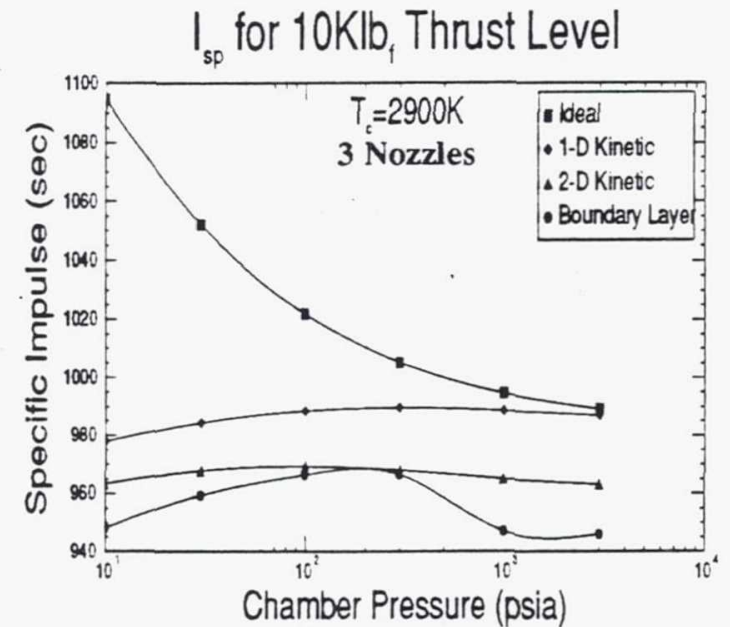

Figure A-25

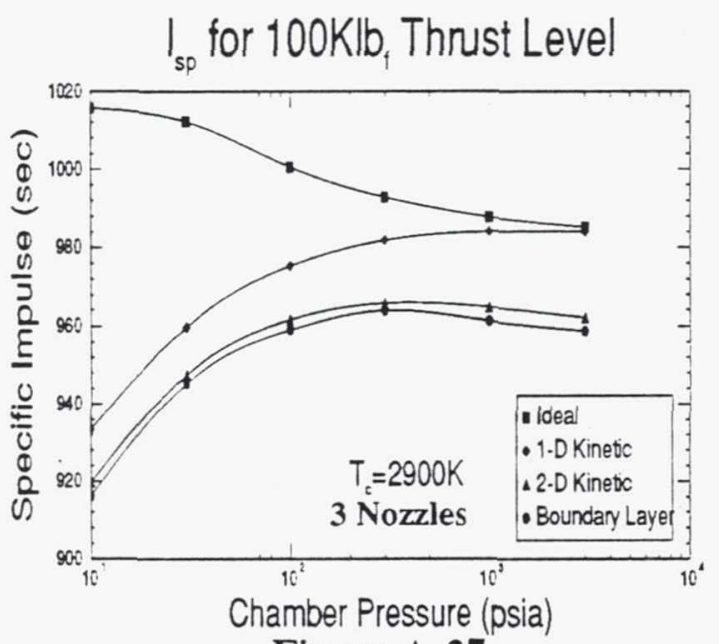

Figure A-27

\section{Nozzle Area Ratio}

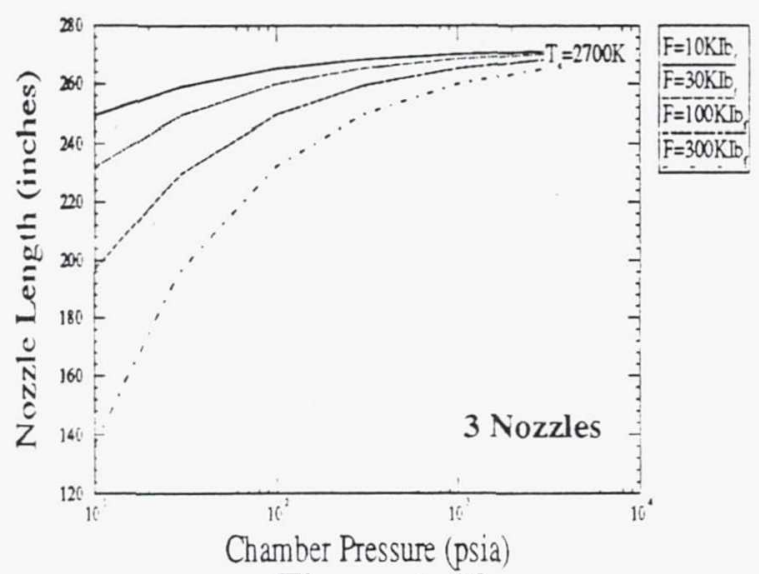

Figure A-29
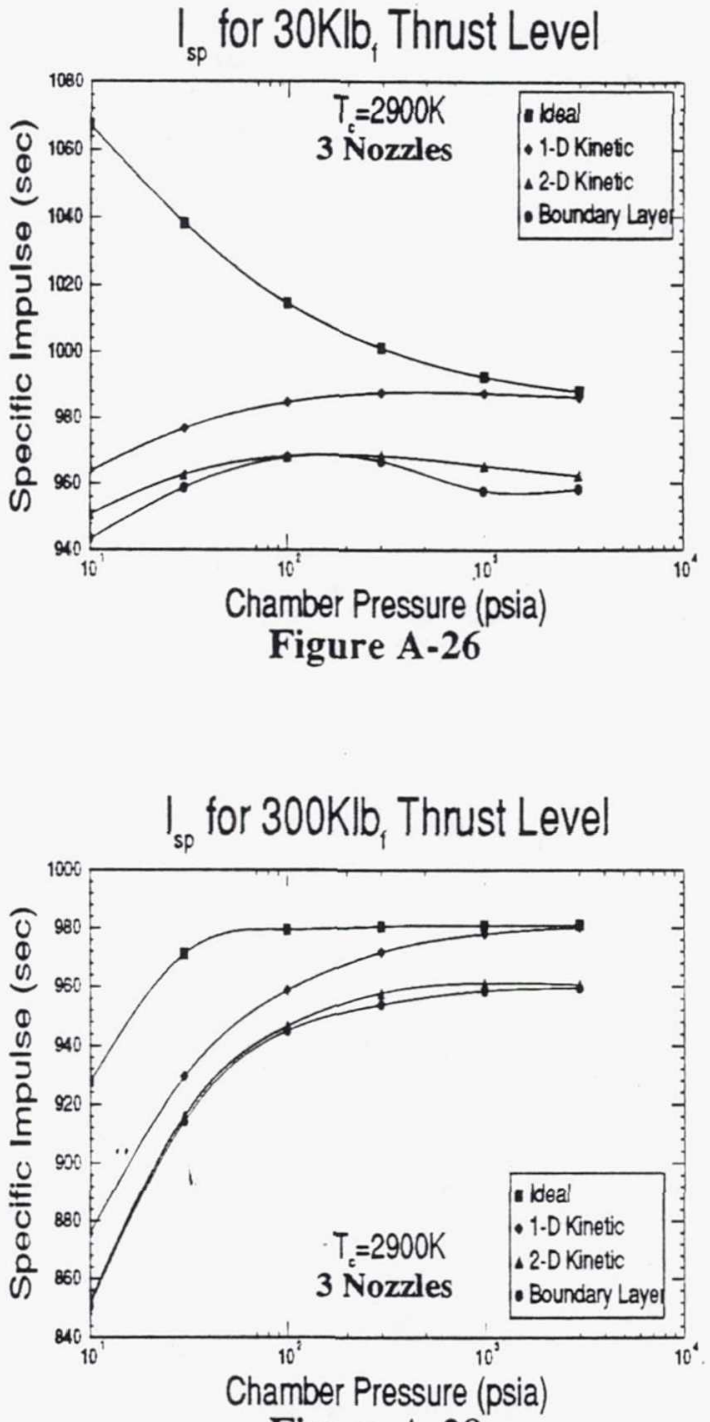

Figure A-28

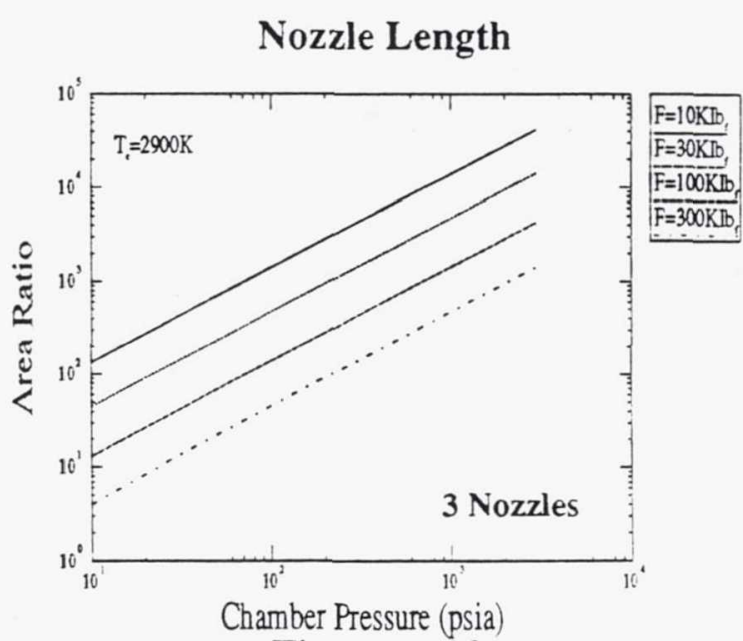

Figure A-30 


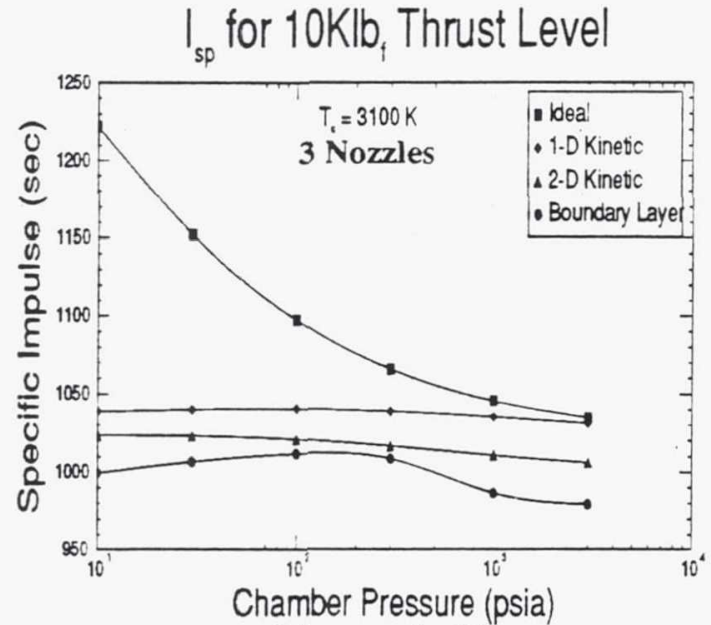

Figure A-31

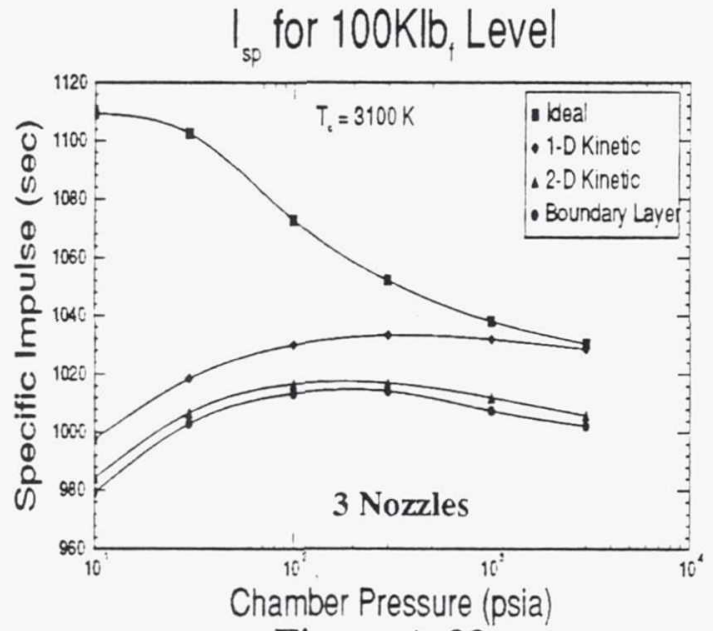

Figure A-33

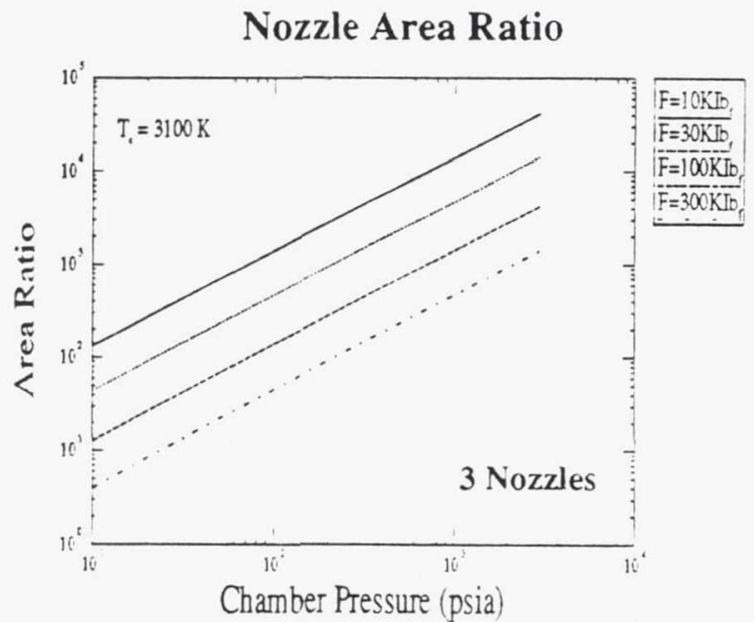

Figure A-35
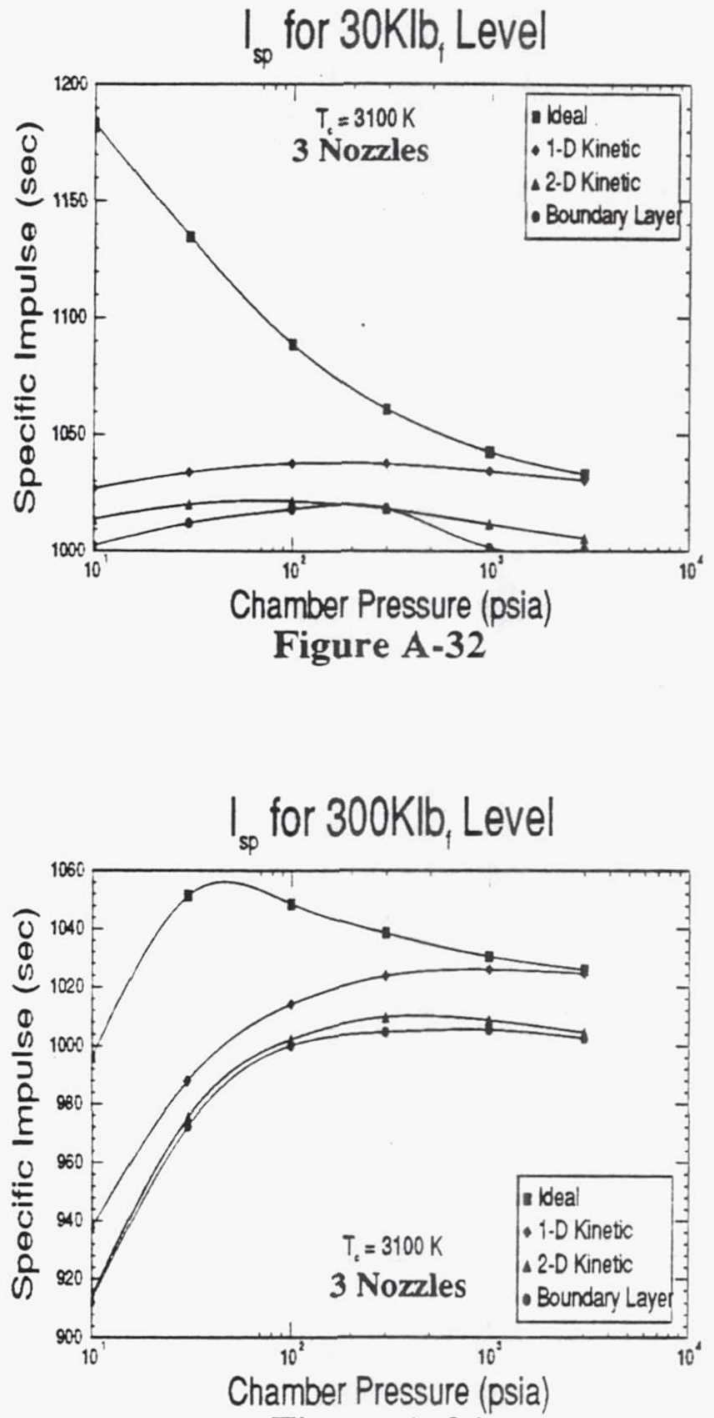

Figure A-34

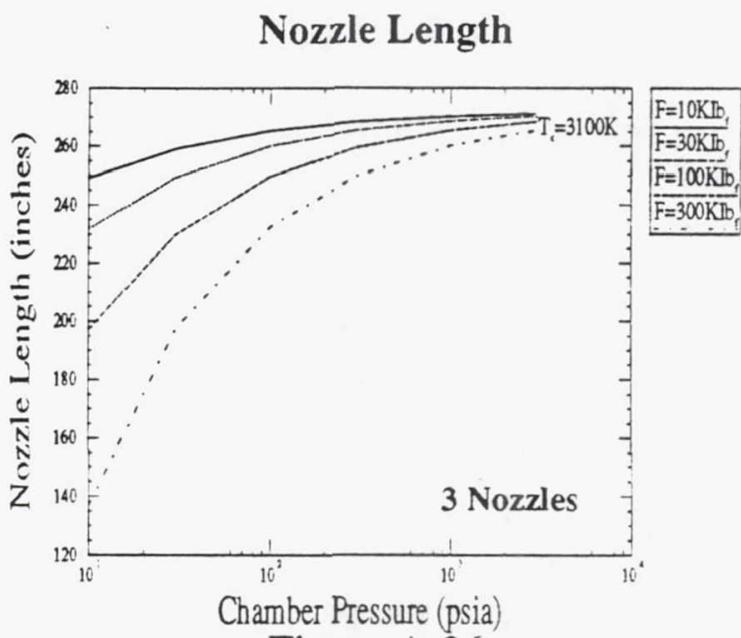

Figure A-36 


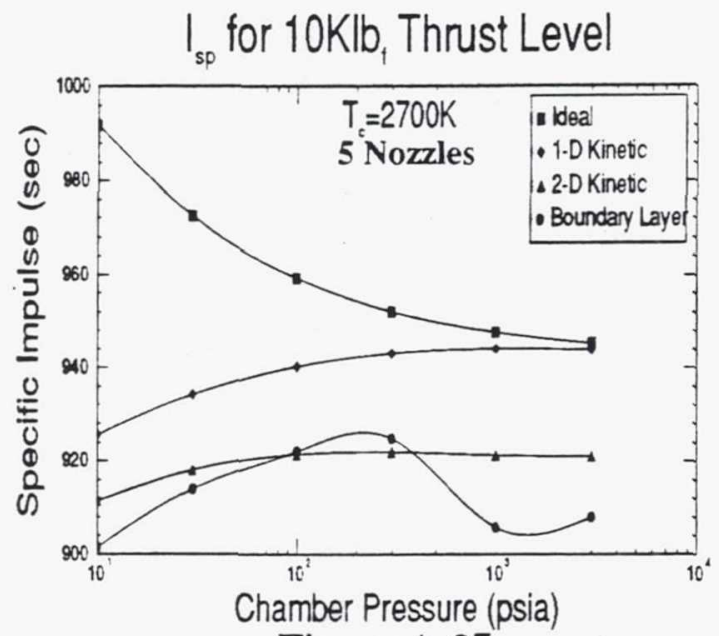

Figure A-37
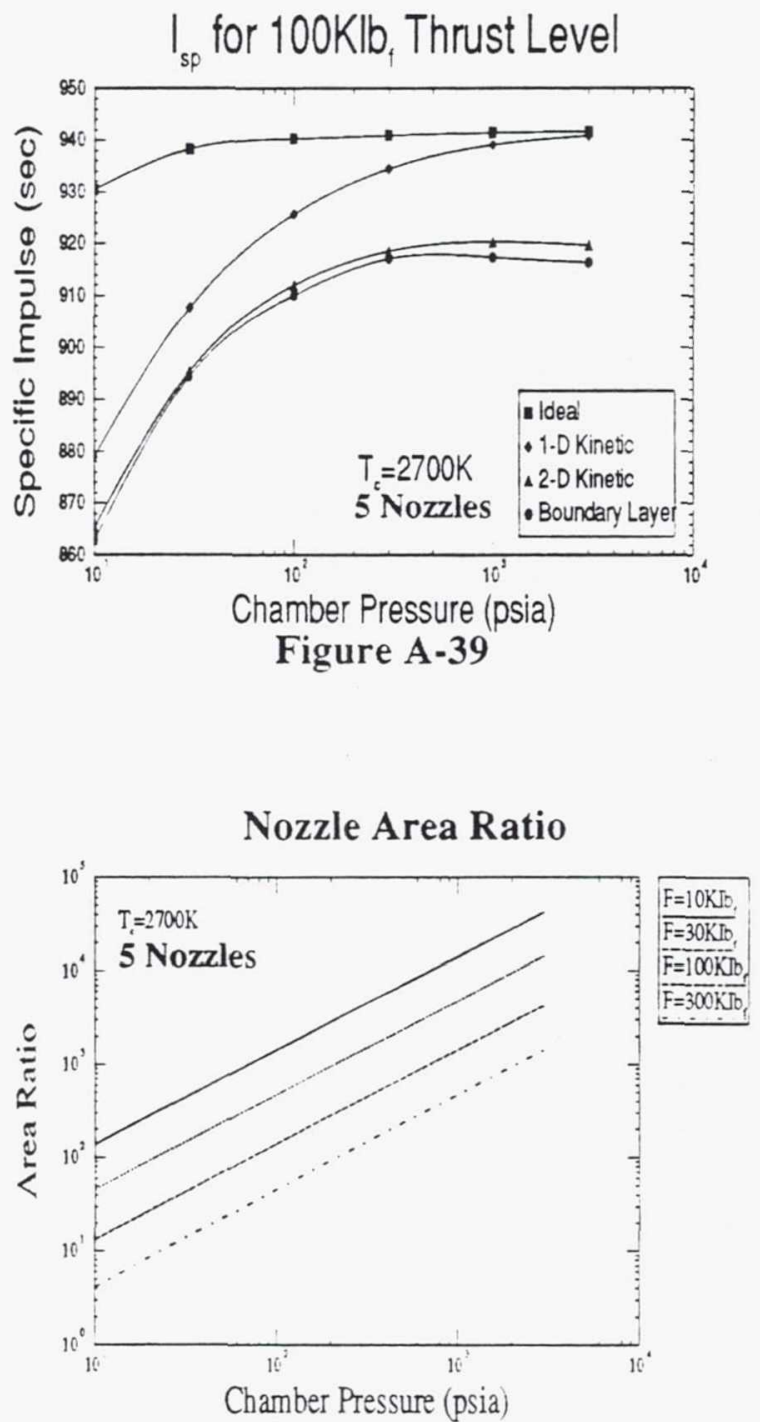

Figure A-41

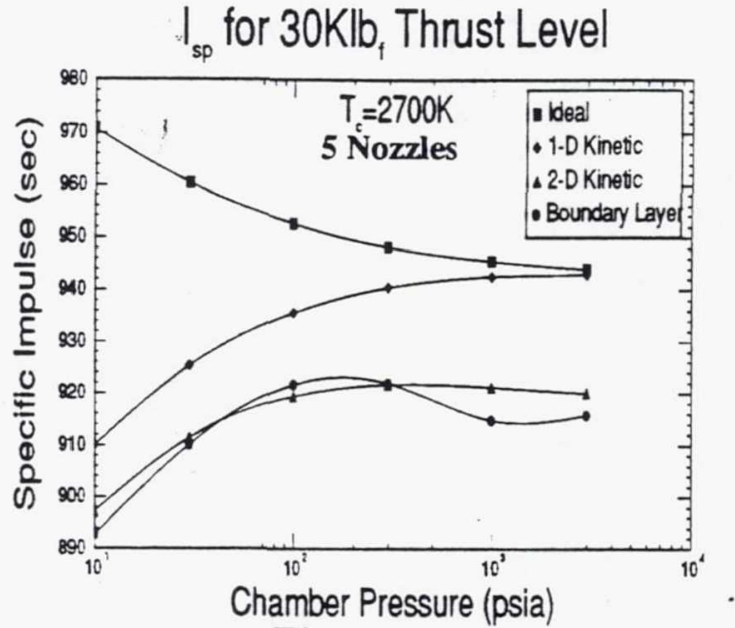

Figure A-38
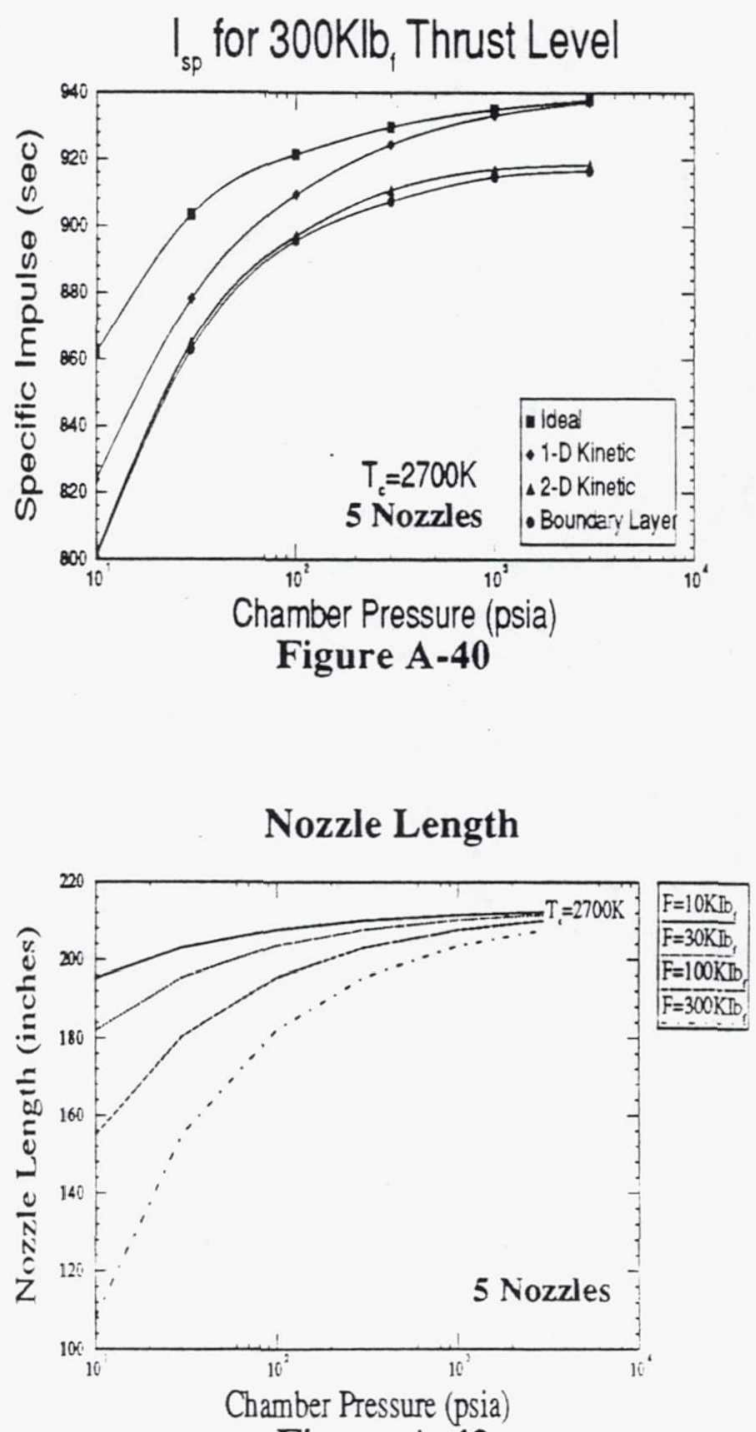

Figure A-42 

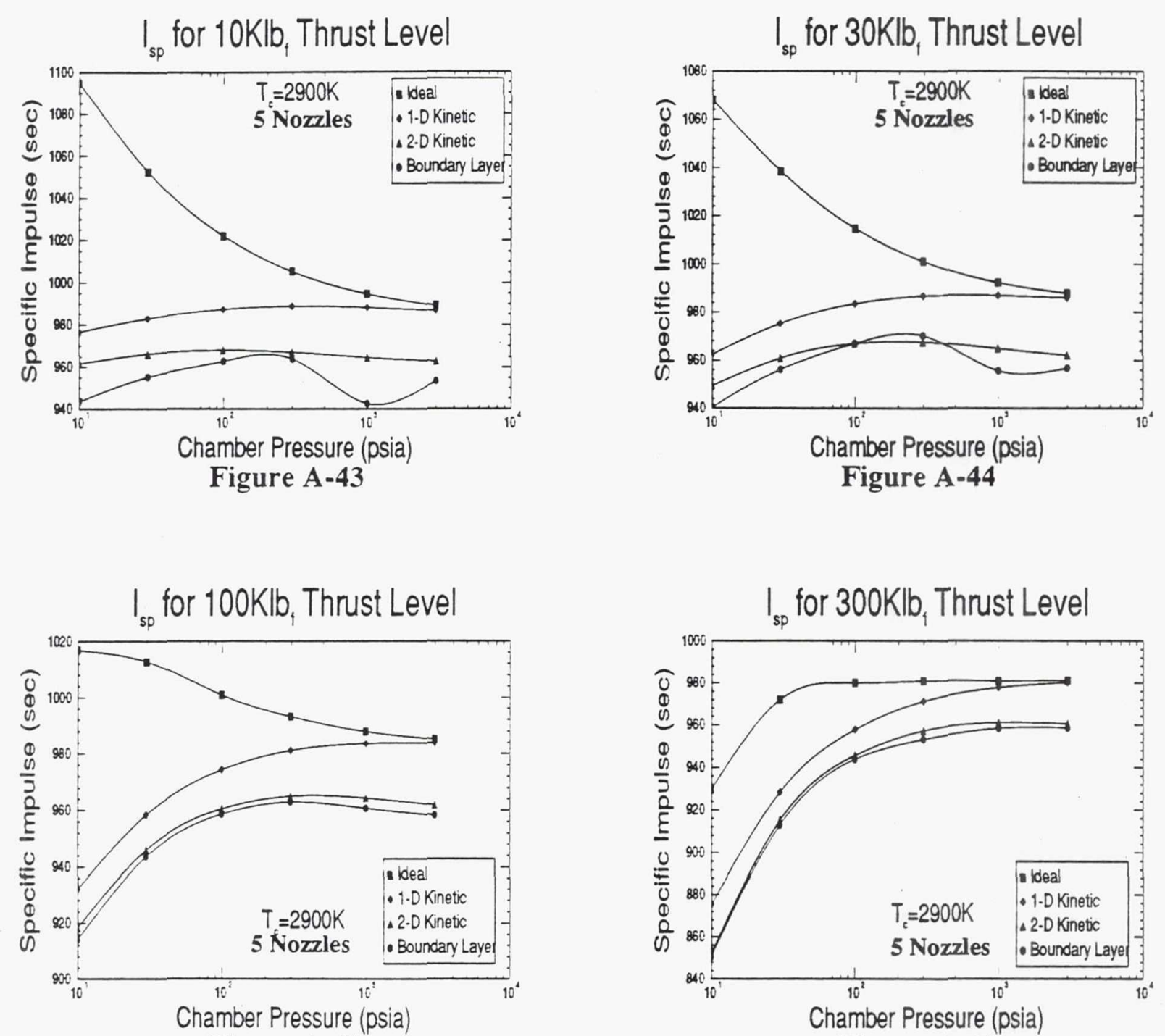

Figure A-45
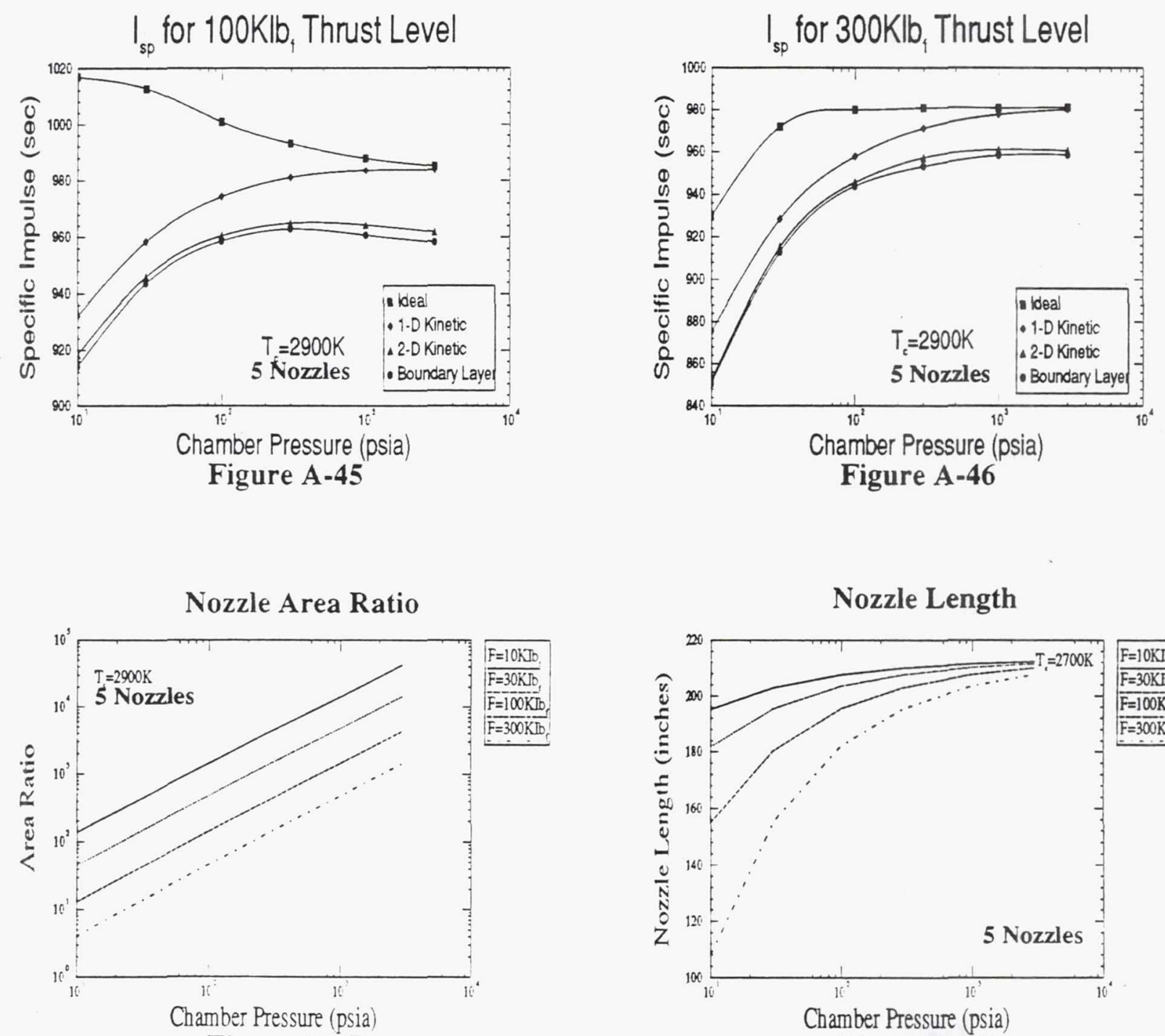

Figure A-47

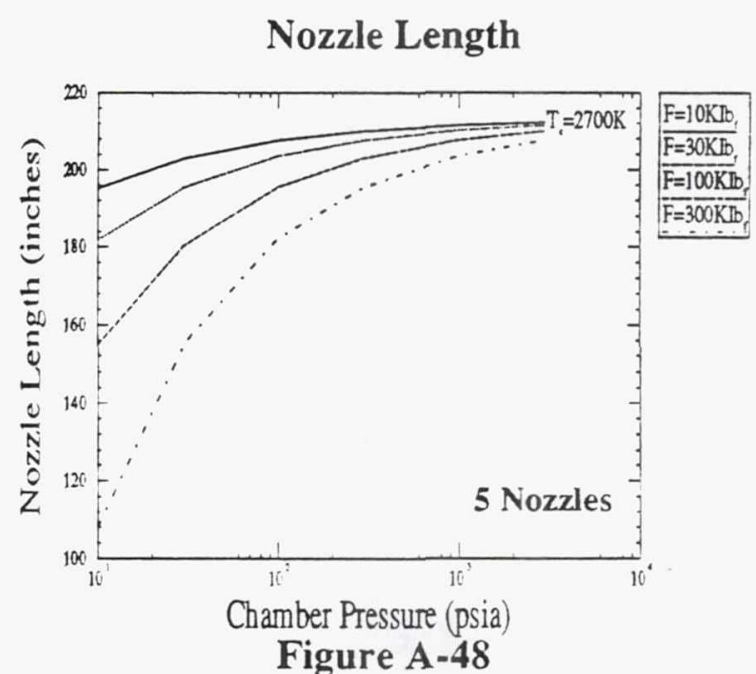




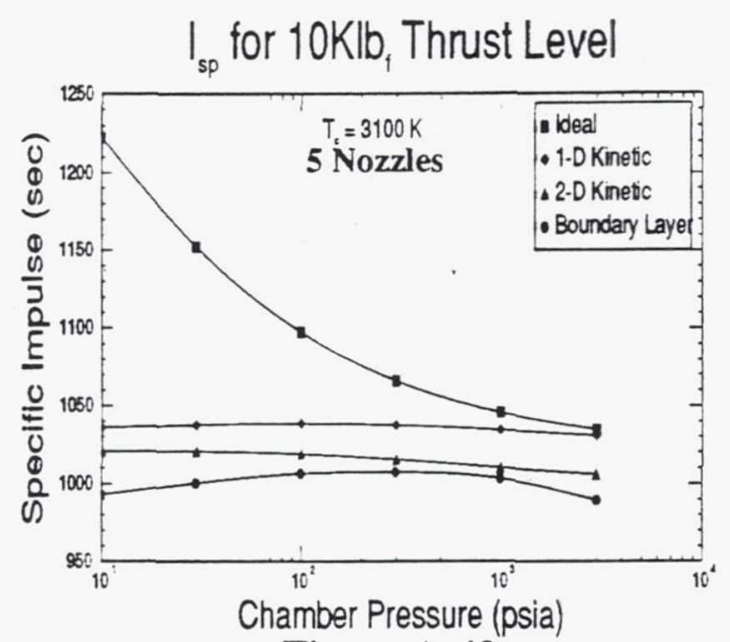

Figure A-49

I for 100Klb, Level

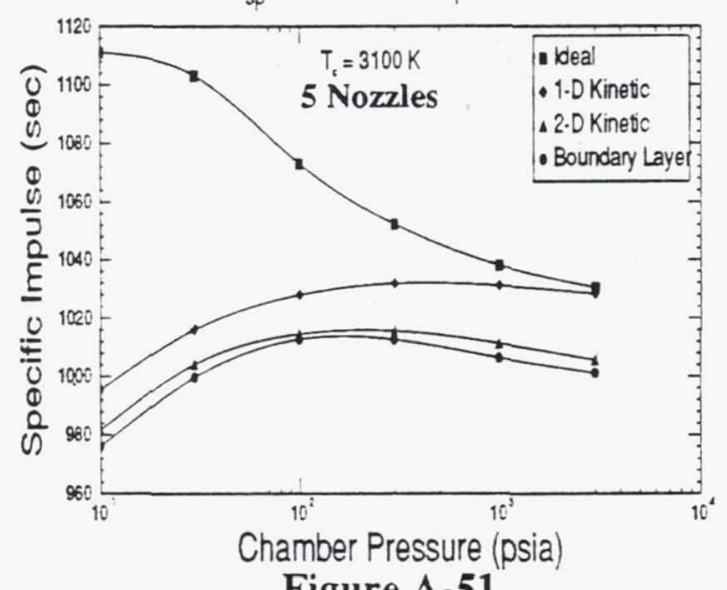

Figure A-51

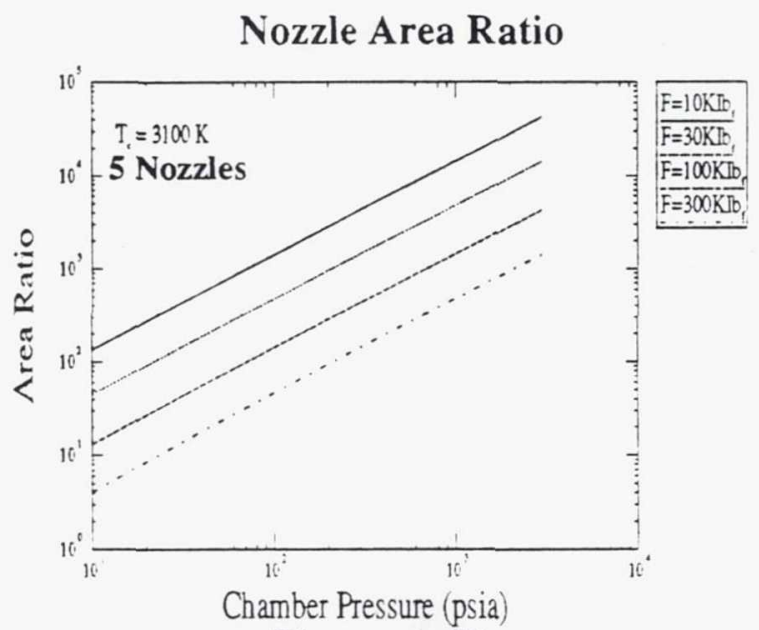

Figure A-53

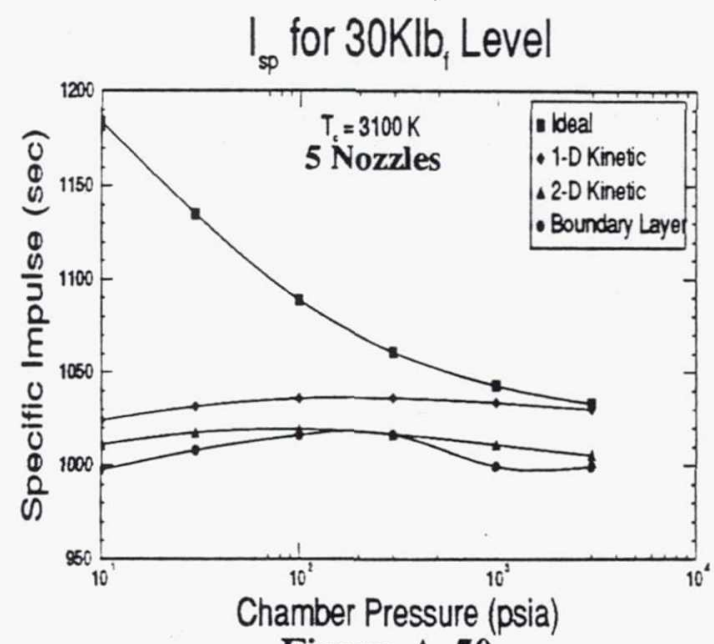

Figure A-50
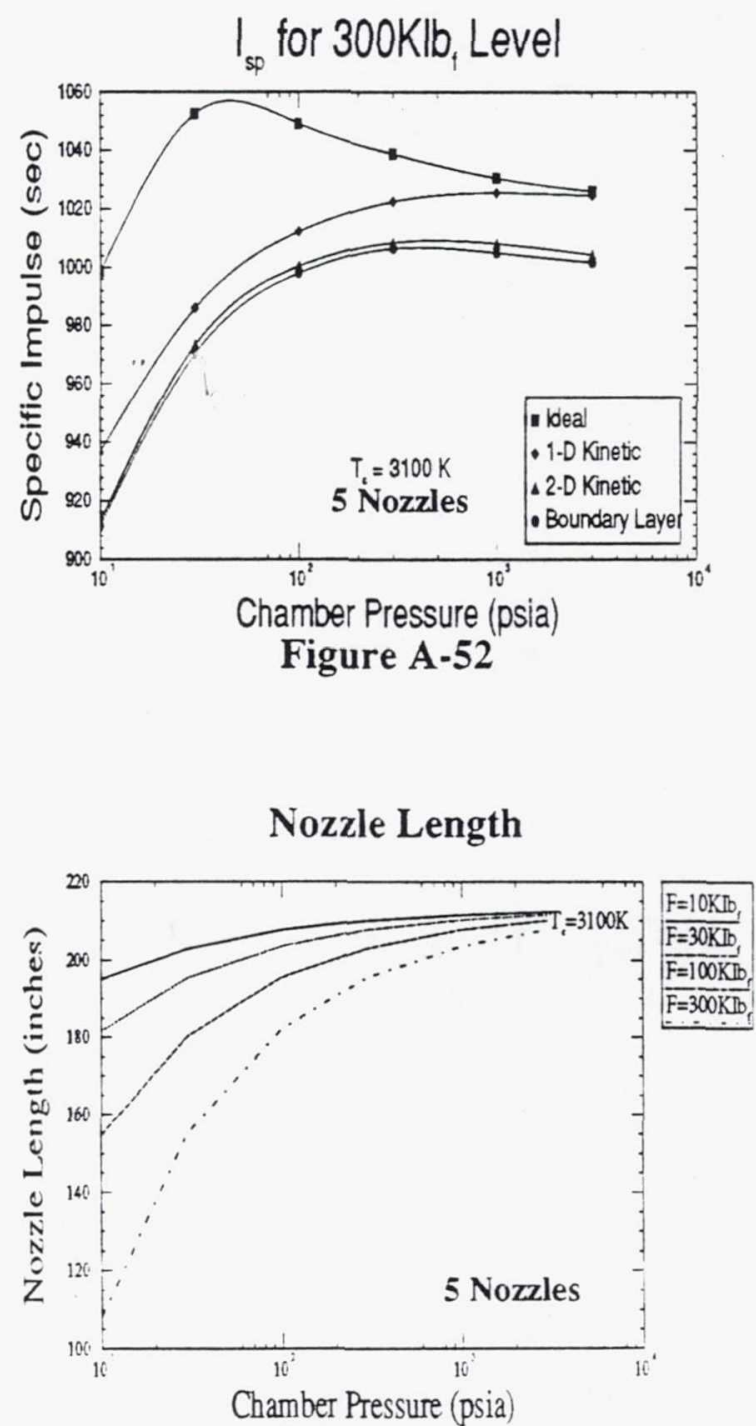

Figure A-54 


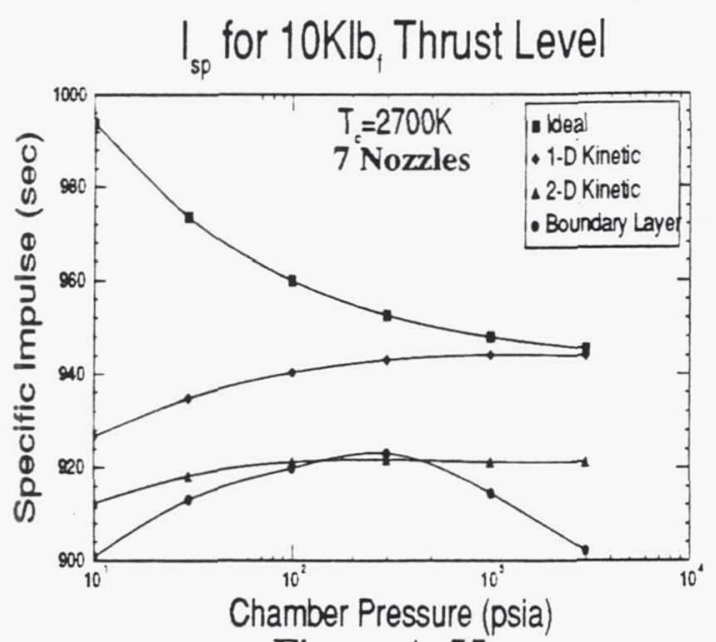

Figure A-55

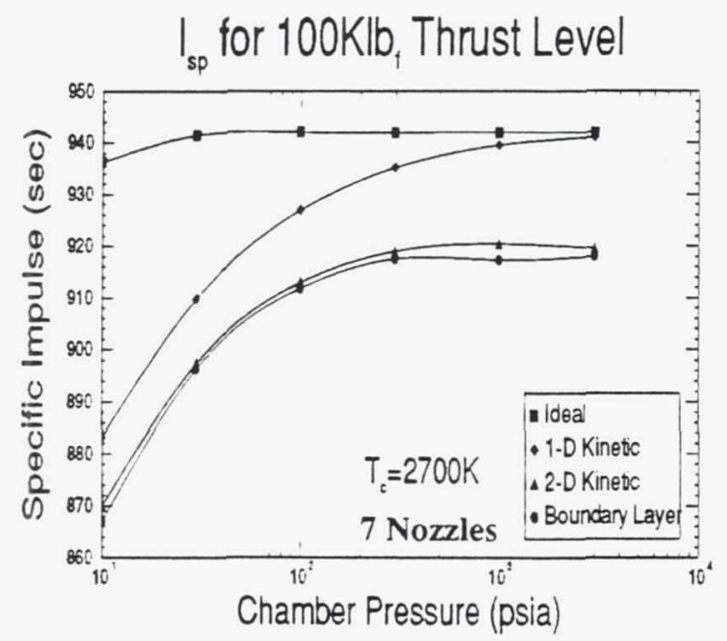

Figure A-57

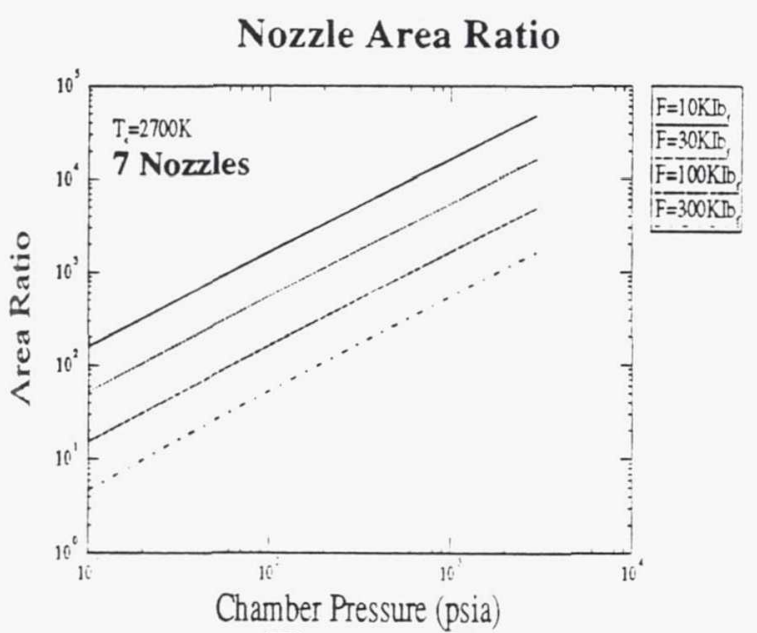

Figure A-59

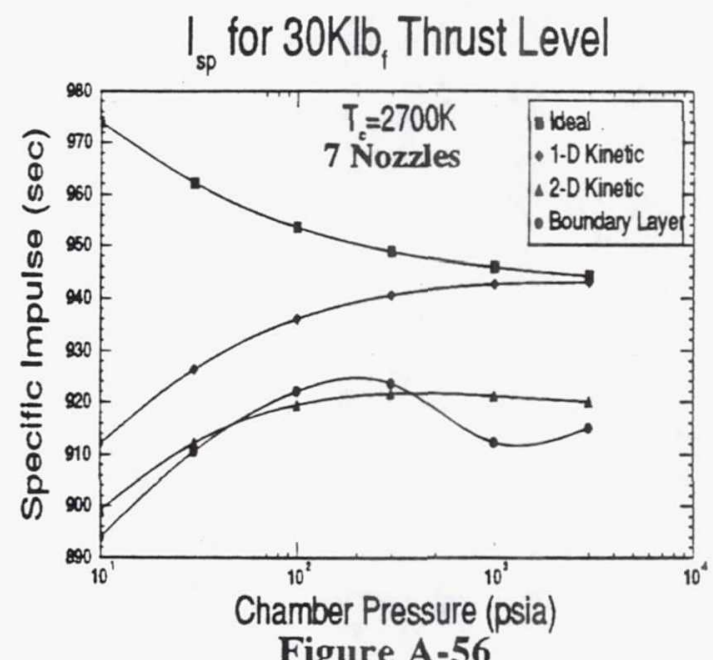

Figure A-56

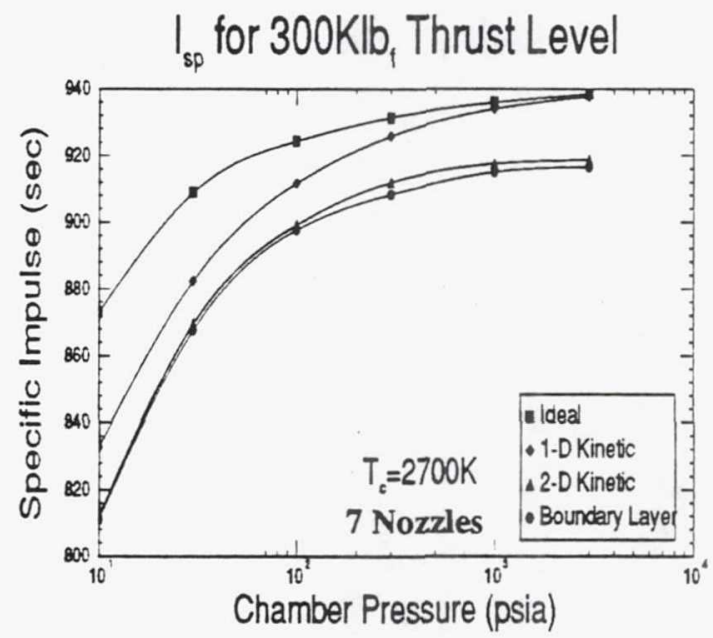

Figure A-58

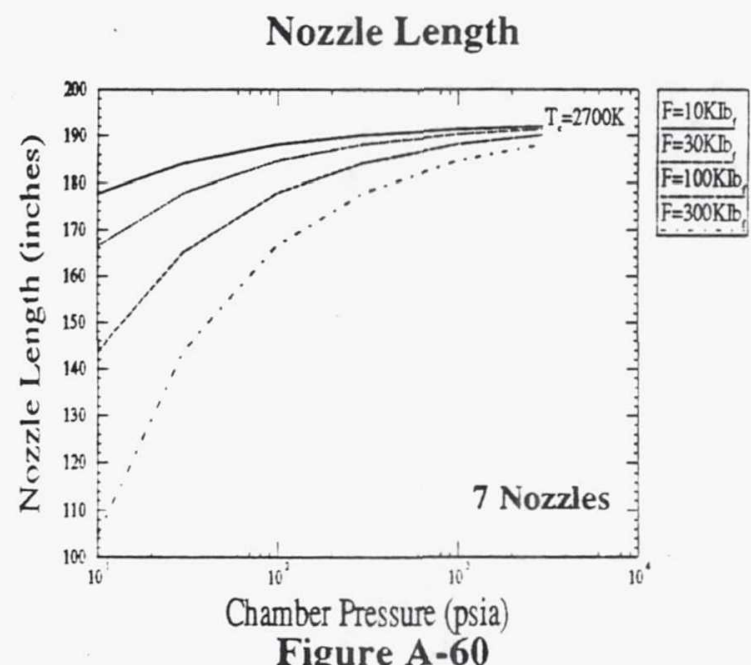

Figure A-60 

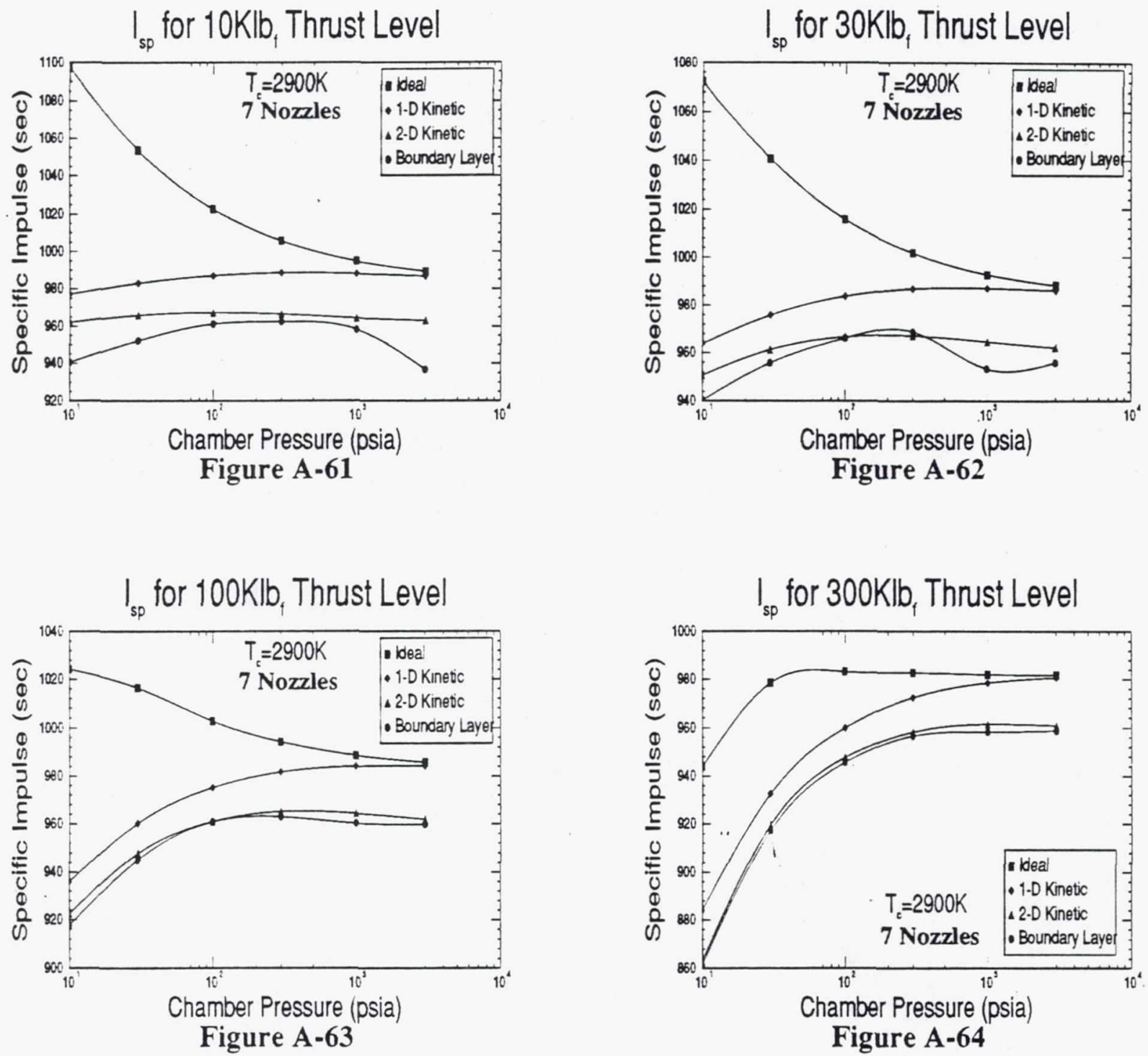

Figure A-64

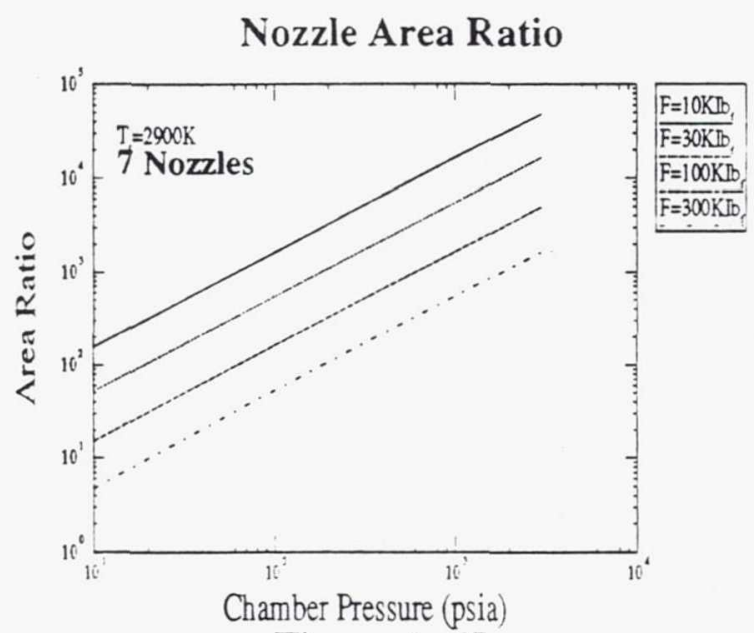

Figure A-65

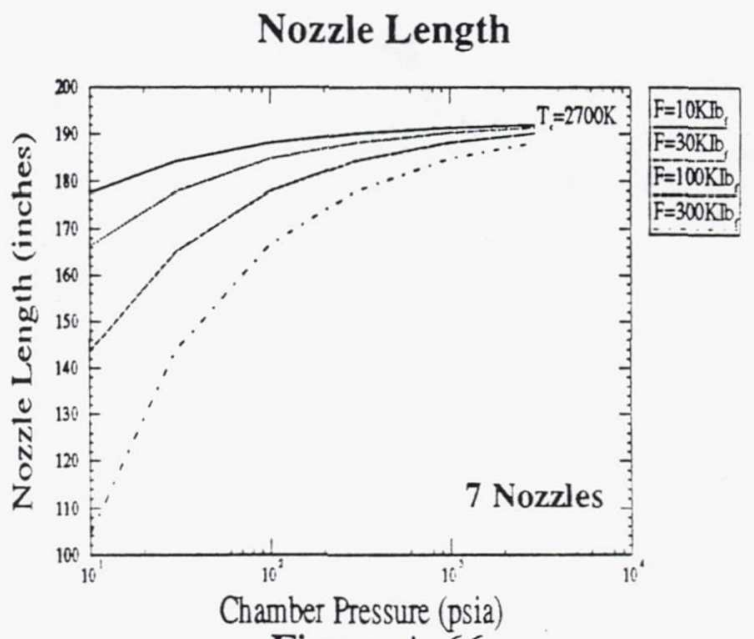

Figure A-66 

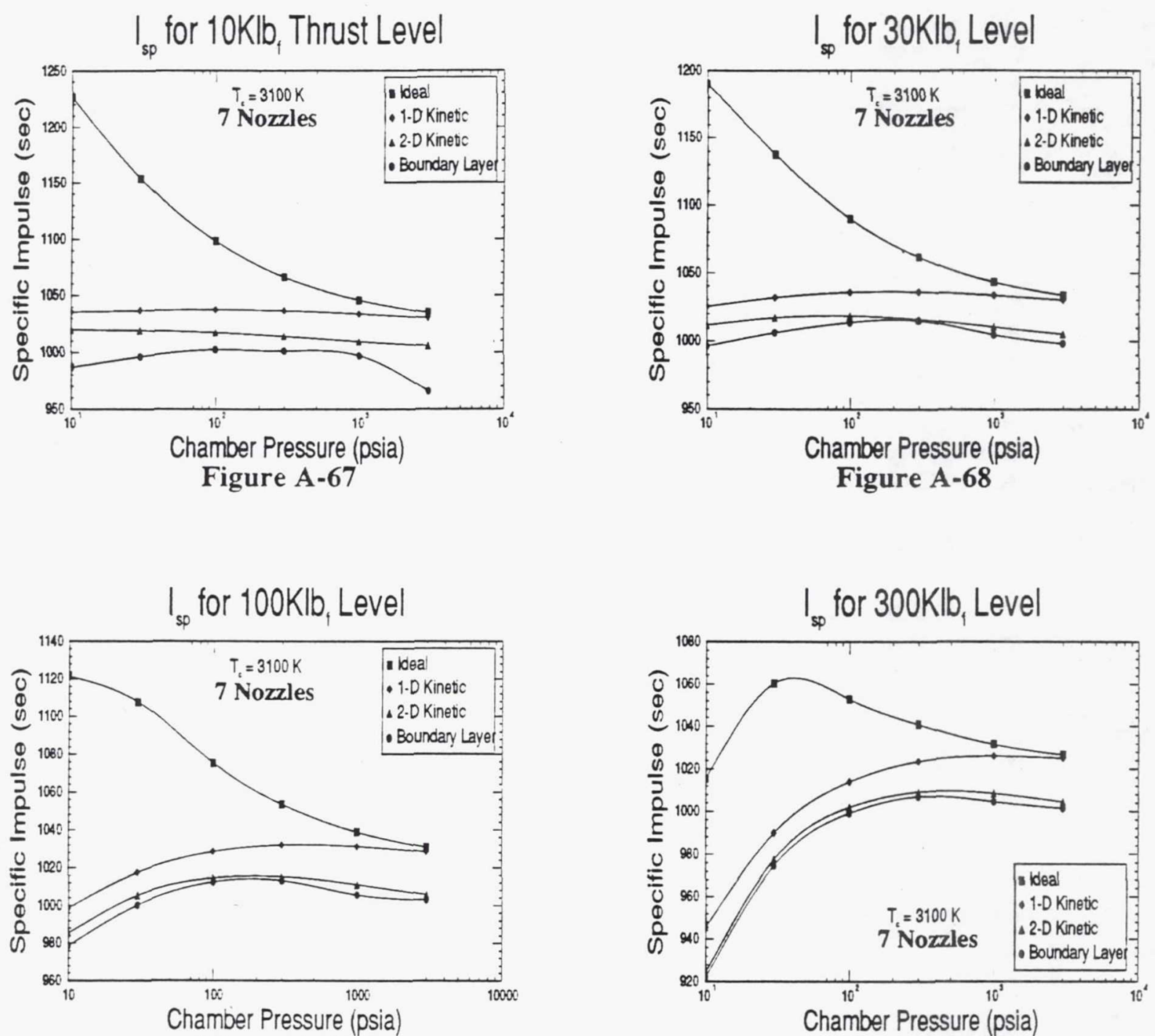

Figure A-69
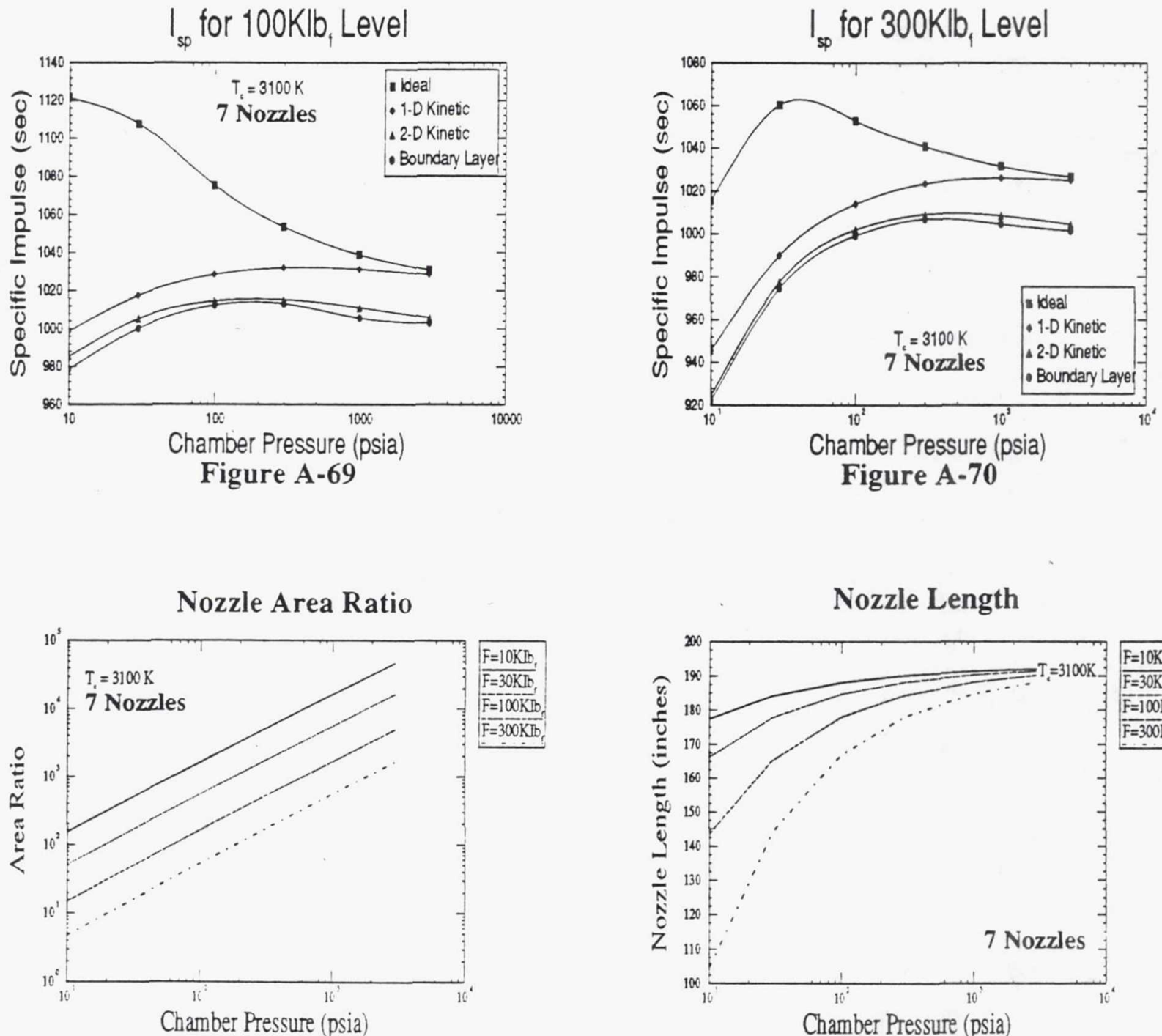

Figure A-71

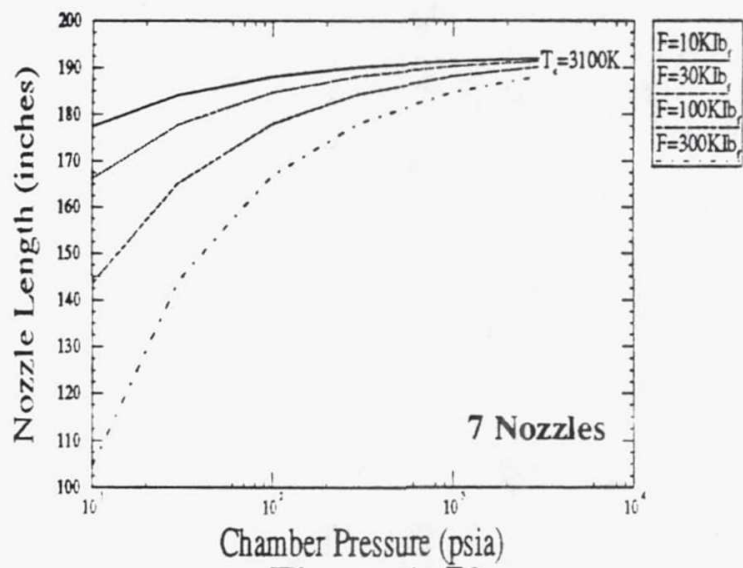

Figure A-72 
Public reporting burden for this collection of information is estimated to average 1 hour per response, including the time for reviewing instructions, searching existing data sources gathering and maintaining the data needed, and completing and reviewing the collection of information. Send comments regarding this burden estimate or any other aspect of this collection of information, including suggestions for reducing this burden, to Washington Headquarters Services, Directorate for information Operations and Reports, 1215 Jefferson Davis Highway, Suite 1204, Arlington, VA 22202-4302, and to the Office of Management and Budget, Paperwork Reduction Project (0704-0188), Washington, DC 20503.

\begin{tabular}{l|l|l} 
1. AGENCY USE ONLY (Leave blank) & 2. REPORT DATE & 3. REPORT TYPE AND DATES COVERED
\end{tabular} Technical Memorandum

4. TITLE AND SUBTITLE

5. FUNDING NUMBERS

Analytical Study of Nozzle Performance for Nuclear Thermal Rockets

3. AUTHOR(S)

Kenneth O. Davidian and Kenneth J. Kacynski

WU $-506-42-72$

7. PERFORMING ORGANIZATION NAME(S) AND ADDRESS(ES)

National Aeronautics and Space Administration

Lewis Research Center

Cleveland, Ohio 44135 - 3191

8. PERFormina ORGANIZATION REPORT NUMBER

E- 6580

9. SPONSORING/MONITORING AGENCY NAMES(S) AND ADDRESS(ES)

10. SPONSORING/MONITORING

National Aeronautics and Space Administration

Washington, D.C. 20546-0001

NASA TM -105251

AIAA - $91-3578$

11. SUPPLEMENTARY NOTES

Prepared for the Conference on Advanced Space Exploration Initiative Technologies cosponsored by AIAA, NASA, and OAI, Cleveland, Ohio, September 4-6, 1991. Responsible person, Kenneth O. Davidian, (216) 433 - 2602.

12a. DISTRIBUTION/AVAILABILITY STATEMENT

12b. DISTRIBUTION CODE

Unclassified - Unlimited

Subject Category 20

13. ABSTRACT (Maximum 200 words)

Nuclear propulsion has been identified as one of the key technologies needed for human exploration of the Moon and Mars. The Nuclear Thermal Rocket (NTR) uses a nuclear reactor to heat hydrogen to a high temperature followed by expansion through a conventional convergent-divergent nozzle. A parametric study of NTR nozzles was performed using the Rocket Engine Design Expert System (REDES) at the NASA Lewis Research Center. REDES used the JANNAF standard rigorous methodology to determine nozzle performance over a range of chamber temperatures, chamber pressures, thrust levels, and different nozzle configurations. A design condition was set by fixing the propulsion system exit radius at five meters and throat radius was varied to achieve a target thrust level. An adiabatic wall was assumed for the nozzle, and its length was assumed to be $80 \%$ of a $15^{\circ}$ cone. The results of this study conclude that although the performance of the NTR, based on infinite reaction rates, looks promising at low chamber pressures, finite rate chemical reactions will cause the actual performance to be considerably lower. Parameters which have a major influence on the delivered specific impulse value include the chamber temperature and the chamber pressures in the high thrust domain. Other parameters, such as two-dimensional and boundary layer effects, kinetic rates and number of nozzles, affect the deliverable performance of an NTR nozzle to a lesser degree. For a single nozzle, maximum performance of 930 seconds and 1030 seconds occur at chamber temperatures of 2700 and $3100 \mathrm{~K}$, respectively.

\section{SUBJECT TERMS}

Nuclear propulsion; Performance prediction

\begin{tabular}{|c|c|}
\hline & $\begin{array}{c}\text { 15. NUMBER OF PAGES } \\
28\end{array}$ \\
\hline & $\begin{array}{r}\text { 16. PRICE CODE } \\
\mathrm{A} 03\end{array}$ \\
\hline $\begin{array}{l}\text { 19. SECURITY CLASSIFICATION } \\
\text { OF ABSTRACT } \\
\text { Unclassified }\end{array}$ & 20. LIMITATION OF ABSTRACT \\
\hline
\end{tabular}

